\title{
Oxidation Kinetics and Strength Degradation of Carbon Fibers in a Cracked Ceramic Matrix Composite
}

\author{
Michael C. Halbig, Army Research Laboratory, Cleveland, $\mathrm{OH}$
}

Ceramic matrix composites (CMCs) are proposed for use in various high temperature structural applications. Proposed applications for $\mathrm{C} / \mathrm{SiC}$ materials include leading edges, control surfaces, nozzles, thrusters, inserted blades, cooled panel heat exchangers and combustion chambers, and friction materials for brakes. Two primary benefits of using $\mathrm{C} / \mathrm{SiC}$ are low weight and high temperature capability compared to other materials. Lighter weight can lead to benefits of increased thrust (performance) and/or increased payload. Higher temperature capability is important for meeting high thermal loads due to combustion gas temperatures in propulsion applications and due to reentry and hypersonic flight conditions in airframe applications. The use of high temperature CMC materials that require little or no cooling can allow for more flexible and simpler designs which can lead to smaller overall vehicle designs and weight savings. Despite the benefits of using $\mathrm{C} / \mathrm{SiC}$ in certain types of applications, one of the barriers to its use is the degradation of the carbon fiber reinforcement, particularly in oxidizing environments. This leads to strength reduction and potential component failure. For single use or short mission applications in oxidizing environments, the oxidation of the carbon fibers may not be a factor. However, in reusable or long term applications, oxidation protection schemes may be necessary.

The oxidation kinetics of carbon fibers in complex composite systems are not well understood. Many studies involve thermogravimetric analysis (TGA) in which weight loss of the composite is monitored over time. These types of studies provide valuable information, however the oxidation of the composites in unstressed and stressed states can be very different, primarily, due to the presence of preexisting cracks. The pre-existing cracks are an as-received property of $\mathrm{C} / \mathrm{SiC}$. The microcracks form during cool down after high temperature processing due to the coefficient of thermal expansion mismatch between the carbon fiber and the silicon carbide matrix. In an unstressed state at elevated temperatures, the formation of silica and the closing of cracks near the processing temperature can seal the cracks and protect the interior of the composite from the outside oxidizing environment. However in many real application conditions, stresses present can prevent cracks from sealing due to wide crack openings and the relatively slow rate of silica growth. Therefore, fibers are more prone to oxidation when the composite is under stress.

Experimental results and oxidation modeling will be presented to discuss carbon fiber susceptibility to oxidation, the oxidation kinetics regimes, and composite strength degradation and failure due to oxidation. Thermogravimetric analysis (TGA) was used to study the oxidation rates of carbon fiber and of a pyro-carbon interphase. The analysis was used to separately obtain activation energies for the carbon constituents within a $\mathrm{C} / \mathrm{SiC}$ composite. TGA was also conducted on $\mathrm{C} / \mathrm{SiC}$ composite material to study carbon oxidation and crack closure as a function of temperature. In order to more closely match application conditions, $\mathrm{C} / \mathrm{SiC}$ tensile coupons were also tested under stressed oxidation conditions. The stressed oxidation tests show that $\mathrm{C} / \mathrm{SiC}$ is much more susceptible to oxidation when the material is under an applied load where the cracks are open and allow for oxygen ingress. The results help correlate carbon oxidation with composite strength reduction and failure. Also since the test conditions allow for easy oxygen ingress, the oxidation kinetics of carbon within a $\mathrm{C} / \mathrm{SiC}$ composite can be studied without the added variable of crack closure.

The results from the experimental analysis were used to provide input for the development of a finite difference model that allows for further analysis of the oxidation kinetics of carbon fibers in a cracked ceramic matrix. Oxygen concentrations and carbon consumption within a cross-section of the composite can be calculated over time during the oxidation process. The effects of such important variables as temperature, diffusion coefficient, reaction rate constant, geometry, and environment can be investigated with the model. The reduction in carbon can be used to predict the composite strength reduction and failure.

As seen from oxidation studies, microstructural analysis, and model development, the oxidation of carbon occurs in two primary regimes, i.e., the diffusion-controlled regime and the reaction-controlled regime. In the reaction-controlled regime, there was a strong temperature dependence. In this regime, component lives were longer and strains to failure were lower in stressed oxidation tests and weight loss rates were lower in TGA tests compared to the trends for the other regime. Microstructural analysis of polished cross-sections tested under stress suggests and the model confirms that the material becomes 
saturated in oxygen. Due to the relatively slow oxygen/carbon reactions and the high oxygen concentration within the composite, oxidation occurred throughout the material. In the diffusion-controlled regime, there was less of a temperature dependence. In this regime, component lives were shorter and strains to failure were higher in stressed oxidation tests and weight loss rates were higher in TGA tests. Microstructural analysis of polished cross-sections tested under stress suggests and the model confirms that there was a sharp gradient in oxygen concentration from the edge up to the moving reaction front of oxidizing carbon with very low oxygen concentrations on the interior side of the reaction front. A shrinking core of the carbon fiber reinforcement was seen from the outer perimeter inward as oxidation progressed.

From a better understating of carbon fiber oxidation, ways to protect the fiber can be determined for different application conditions, such as environment, temperature, stress, and duration. The carbon fibers can be protected through several different approaches that target oxidation inhibition at either the fiber, interphase, matrix, external coating or a combination of these. Oxidation inhibited $\mathrm{C} / \mathrm{SiC}$ materials were evaluated in TGA and stressed oxidation conditions. The inhibiting approaches consisted of boroncontaining particulates in the matrix and/or a CBS (carbon-boron-silicon) external coating. The results show that the approaches were effective in prolonging life and retaining strength even when the $\mathrm{C} / \mathrm{SiC}$ materials were under stress in a high temperature, oxidizing environment. The purpose of these oxidation inhibitors is to form glasses and solid oxides that seal cracks. However the methods were only effective in sealing cracks at the stress of $10 \mathrm{ksi}$ and not at the higher stress of $25 \mathrm{ksi}$. 


\title{
Oxidation Kinetics and Strength Degradation of Carbon Fibers in a Cracked Ceramic Matrix Composite
}

\author{
Michael C. Halbig
}

U.S. Army Research Laboratory - Vehicle Technology Directorate located at NASA Glenn Research Center, Cleveland, Ohio

Presented at the $28^{\text {th }}$ International Cocoa Beach Conference and Exposition on Advanced Ceramics \& Composites, January 25-30, 2004, Cocoa Beach, Florida. 


\section{Acknowledgements}

Oxidation model development and evaluation of oxidation inhibited $\mathrm{C} / \mathrm{SiC}$ was supported by the Propulsion Research \& Technology Program

- CMC Life Prediction Task (S. Levine)

- Environmental Durability of CMCs Task (J.D. Kiser)

TGA - D. Humphrey with QSS at NASA GRC

Stressed Oxidation - D. Brewer, R. Pawlik, J. Zima at NASA GRC and additional tests at the Southern Research Institute (SoRI)

Tensile Test - SoRI

Oxidation Model Development and Theory - J. Cawley and A. Eckel 


\section{Outline}

- Introduction - GRC Research in CMCs

- C/SiC Cracks/Oxidation Pathways

- Oxidation Kinetics

- Oxidation Studies of Carbon Constituents and $\mathrm{C} / \mathrm{SiC}$ Composites

- Strength Reduction and Lifetime Tests of C/SiC Composites

- Modeling the Oxidation of Carbon Fibers in a Cracked Ceramic Matrix Composite

- Evaluation of Oxidation Inhibited C/SiC Composite Materials 


\section{NASA GRC's Role in Ceramic Material and Component Development}

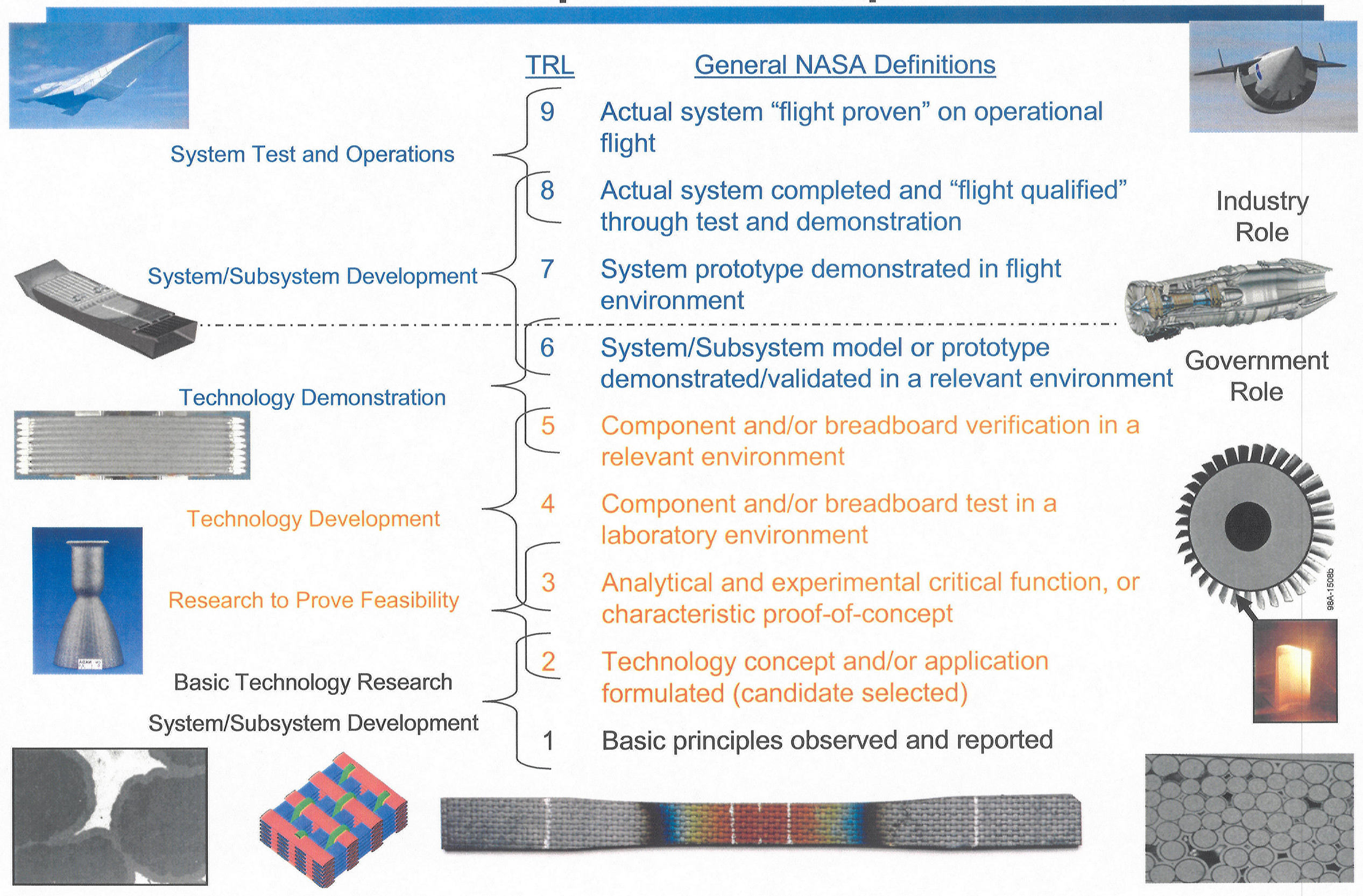




\section{Potential Applications for CMC Components in Aerospace}
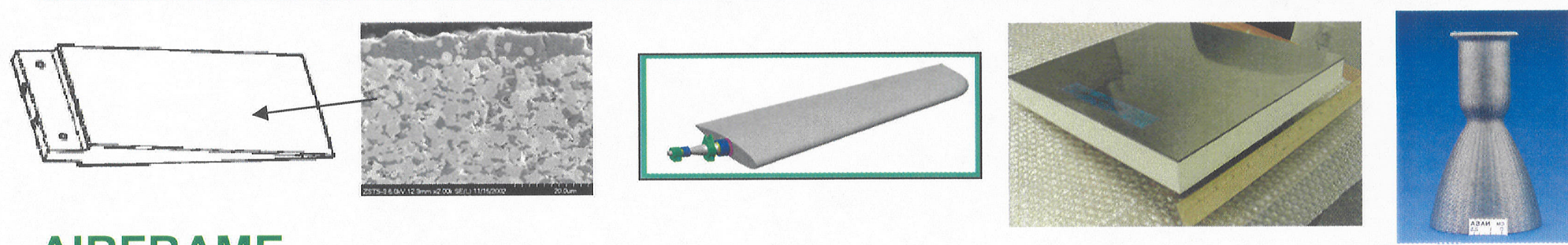

\section{AIRFRAME}

Leading Edges: Blunt, sharp, and cooled leading edges, nose and nose skirt

Hot Structures: Control surfaces, elevons, ruddervators, flaperons, body flaps, integrated panels Acreage Surfaces: Windward TPS panels

Seals: TPS seals, control surface seals, penetration seals

\section{PROPULSION}

Turbomachinery Components: Inserted blades, blisks, stators and rotors, gas path ducting, tip seals, and housings Actively-cooled Components: Cooled panel heat exchangers and combustion chambers (hot gas flow path), nozzles (ramps, bells, extensions), and manifolds Uncooled Thin Wall Structures: Nozzles (radiation cooled), combustion chambers, manifolds, thrust cells, and ducts
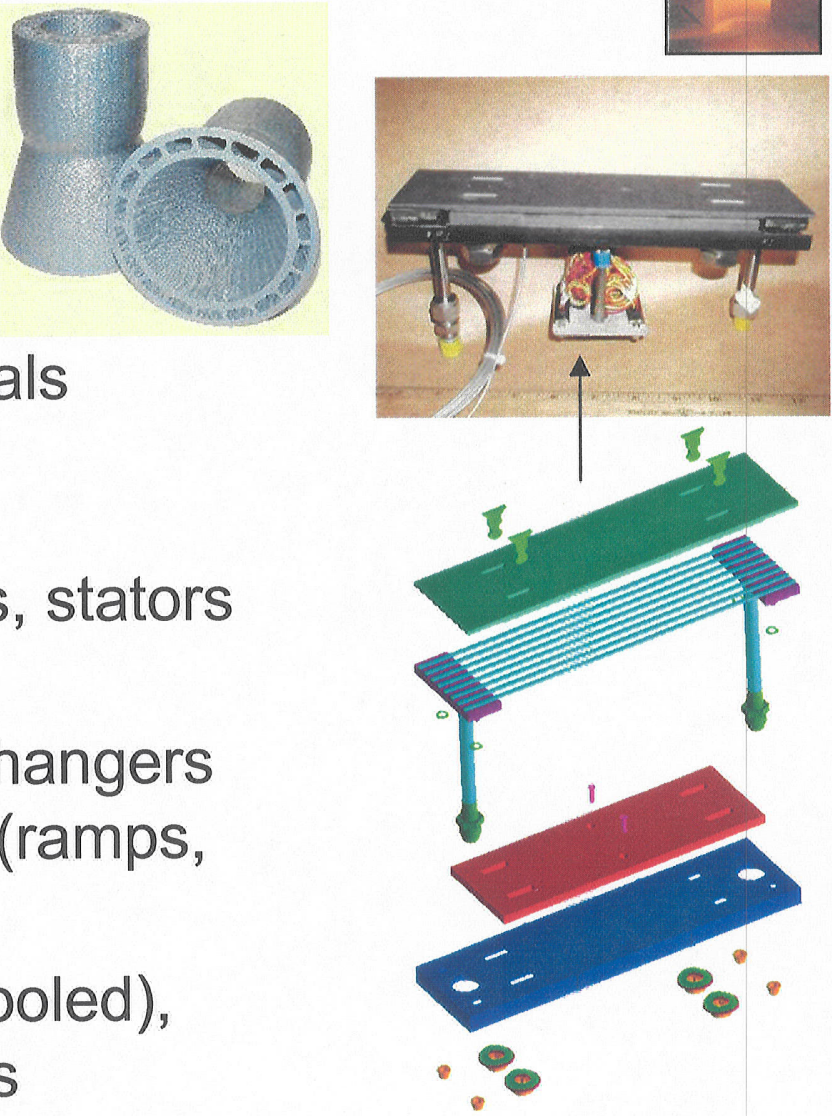


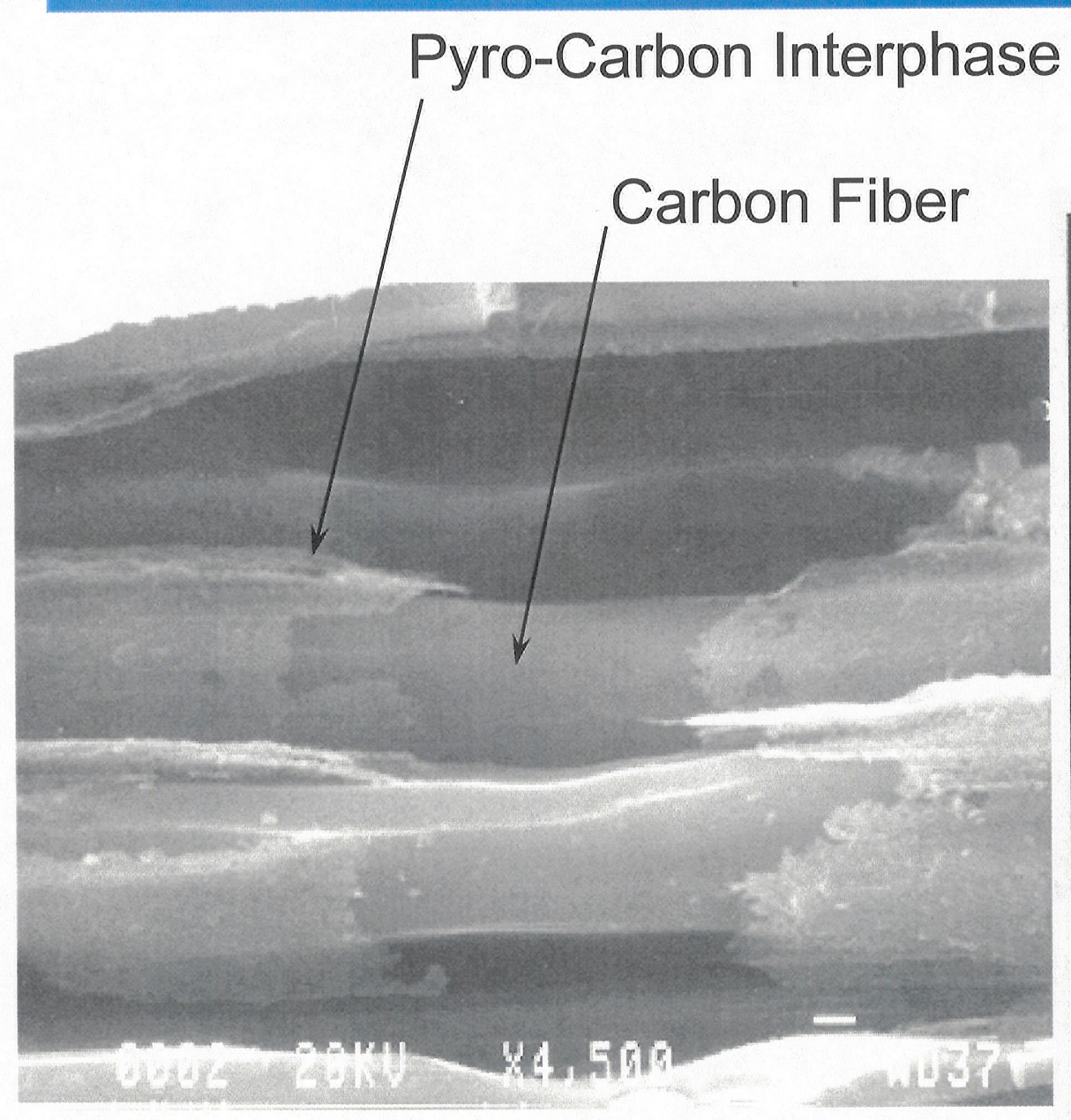
SiC Matrix Cracks

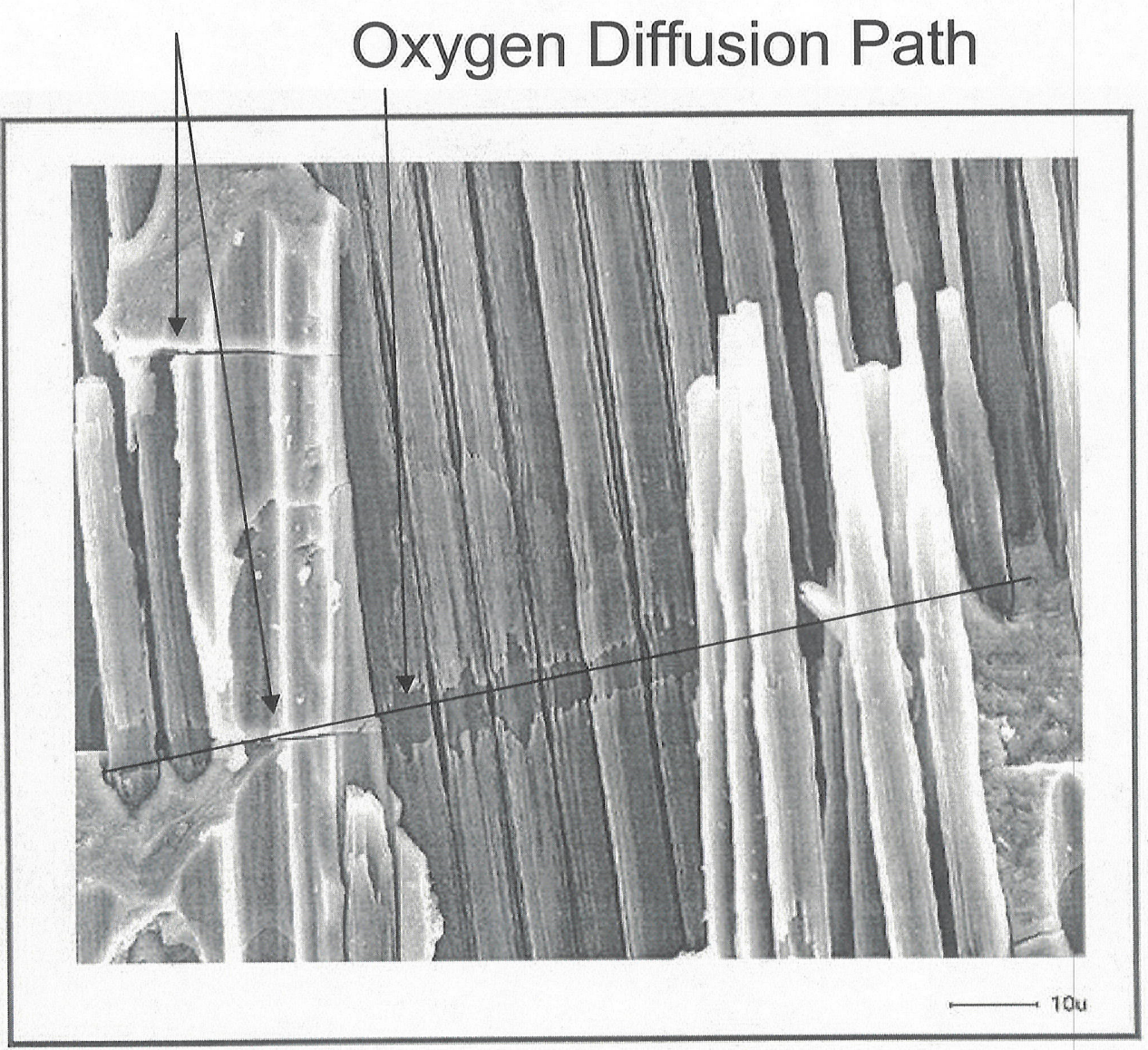

$550^{\circ} \mathrm{C}\left(1022^{\circ} \mathrm{F}\right), 25 \mathrm{ksi}(172 \mathrm{MPa})$ Fracture surface

$1454^{\circ} \mathrm{C}\left(2650^{\circ} \mathrm{F}\right), 10 \mathrm{ksi}(69 \mathrm{MPa})$ Fracture surface 


\section{Oxidation Kinetics Regimes}

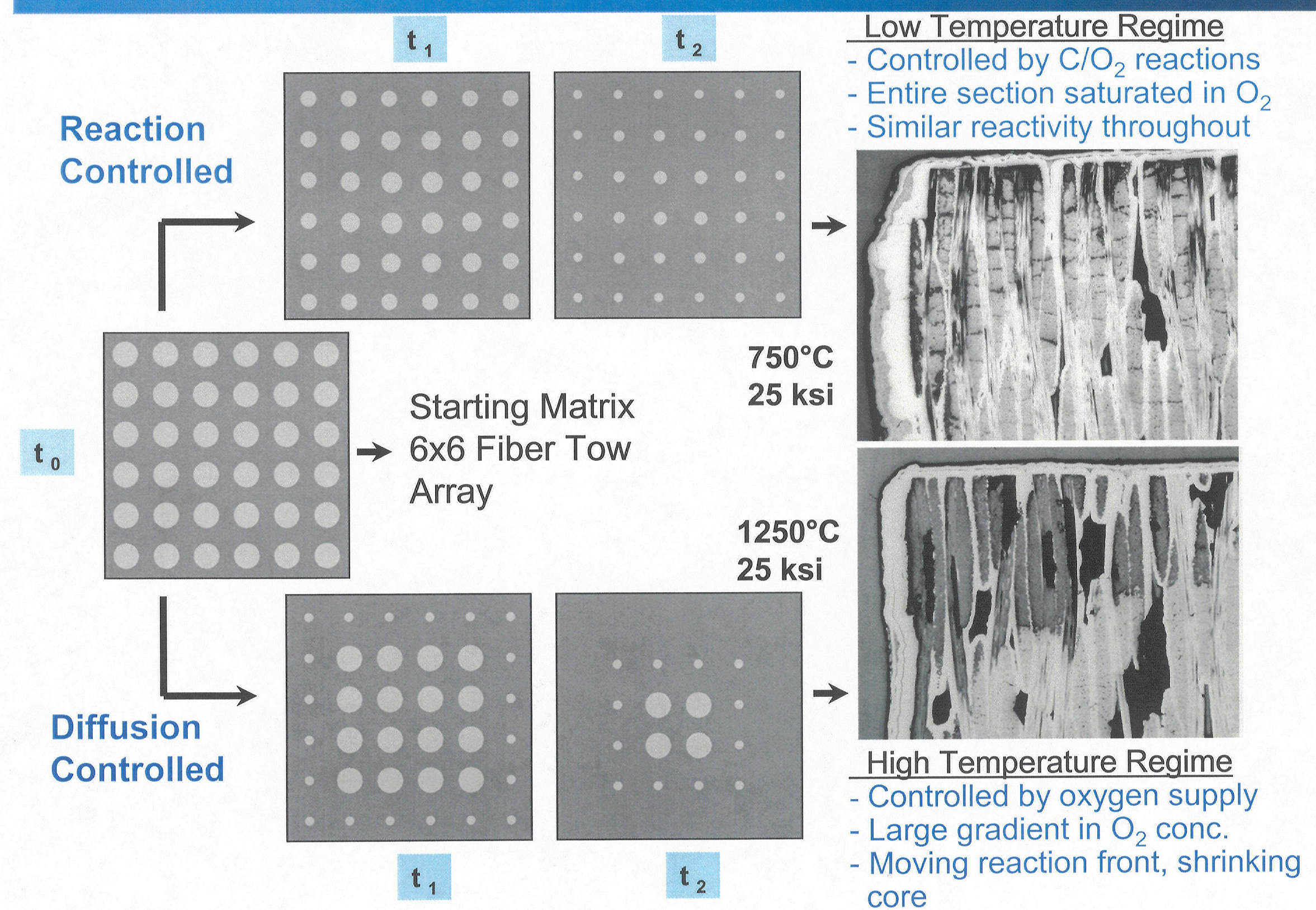




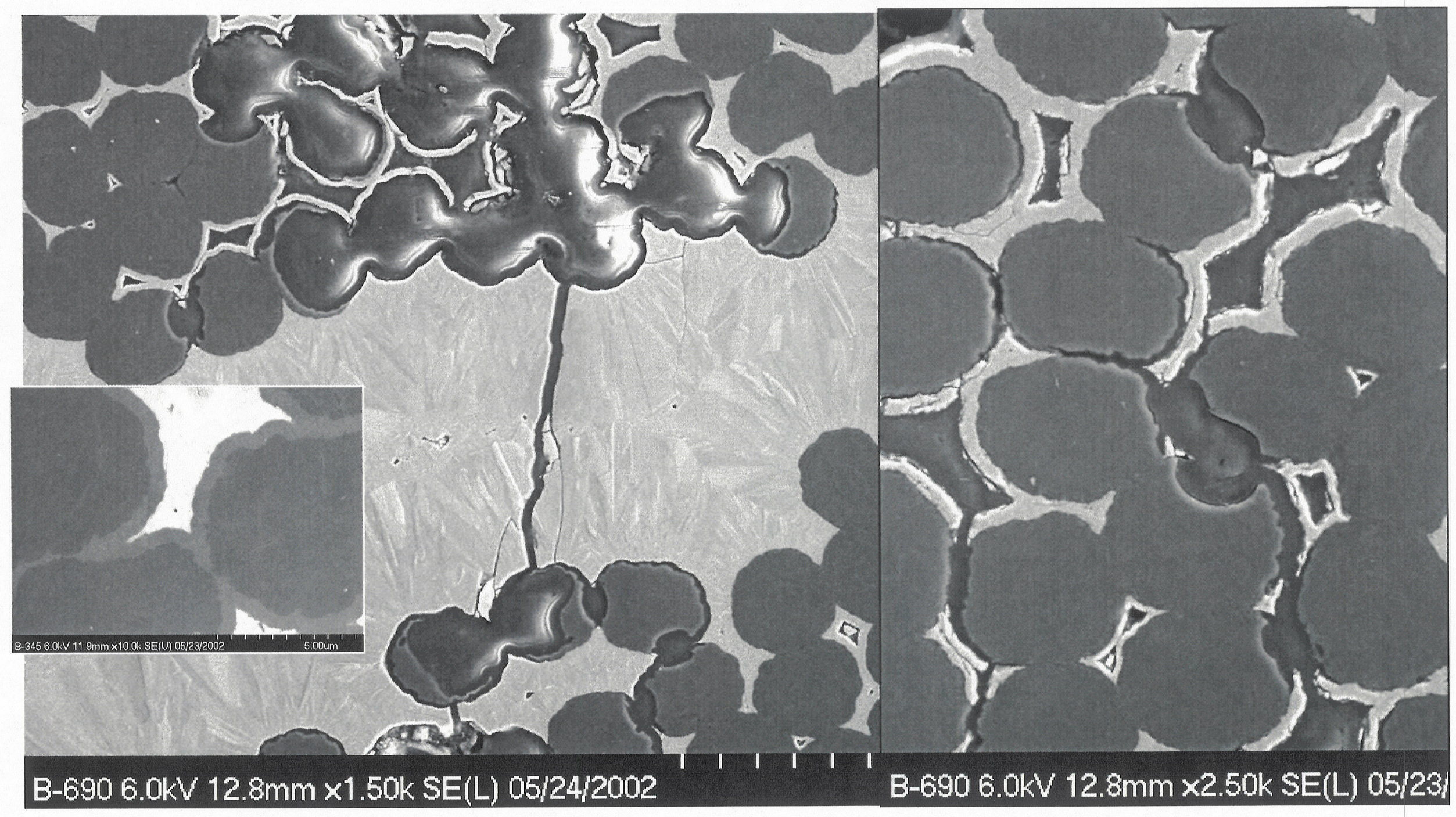




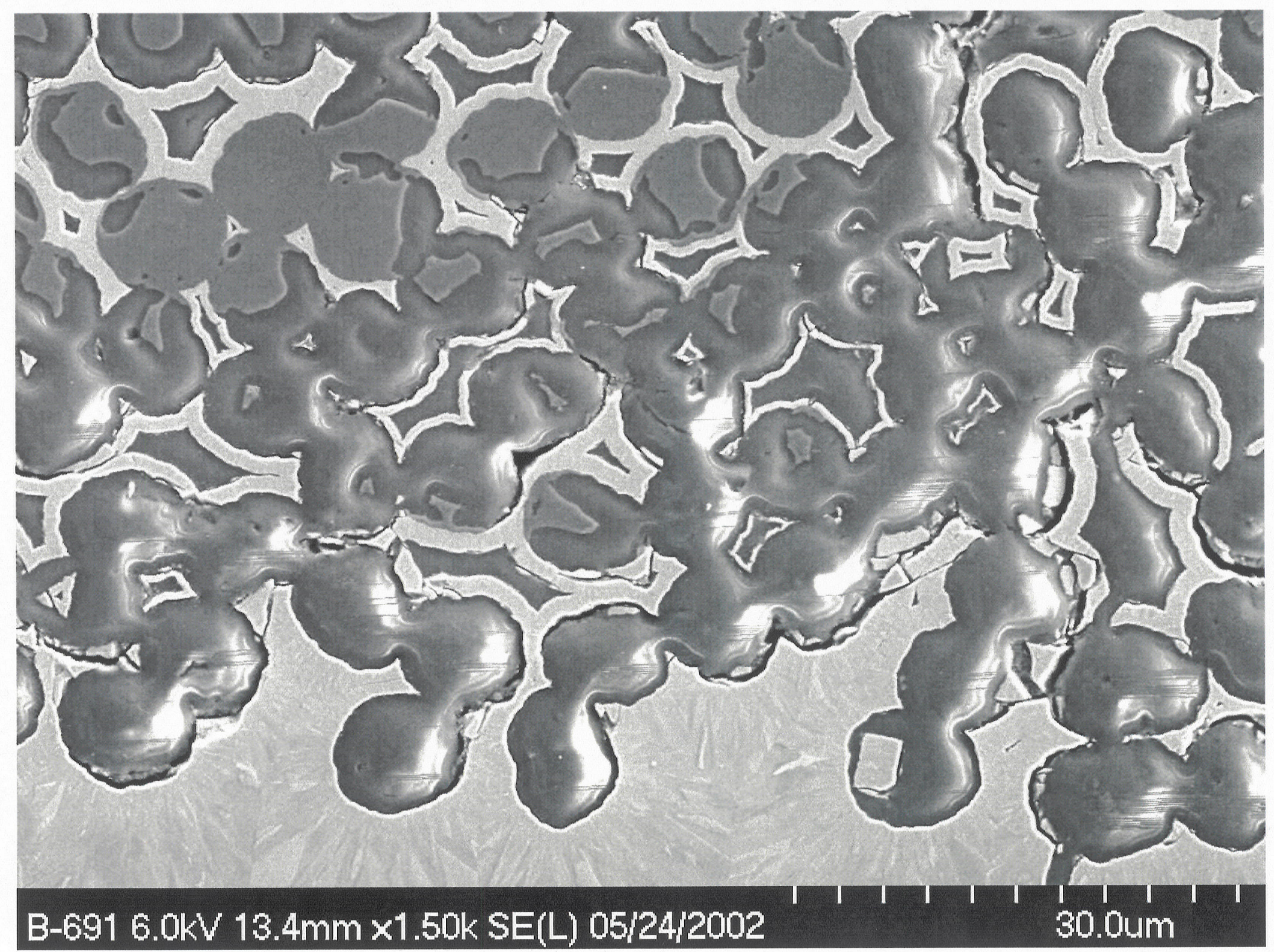




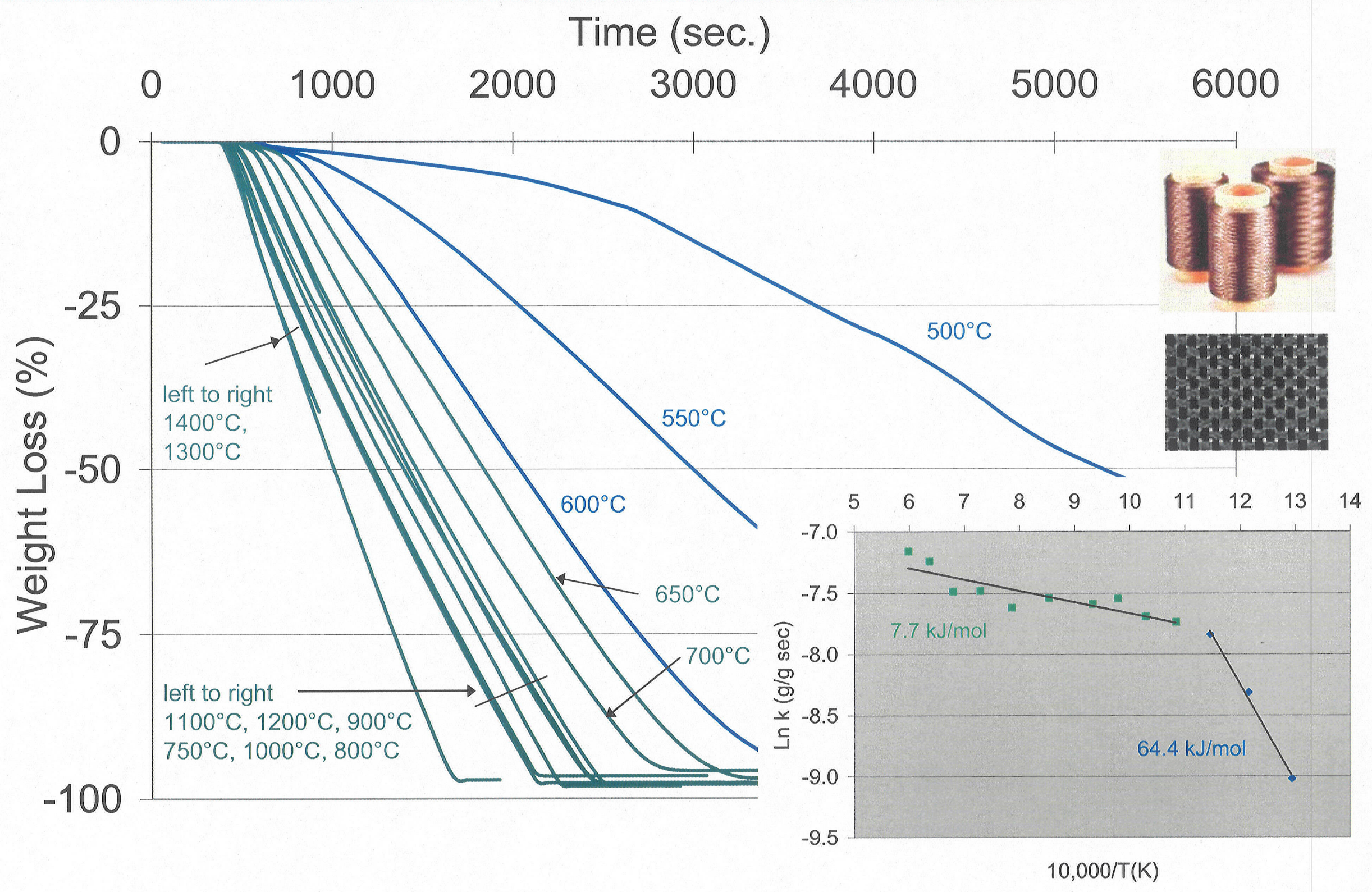




\section{Additional TGA Data of Uncoated T300 Carbon Fiber}

\section{Percent Weight Loss Versus Time (oxygen flowing at $100 \mathrm{ccm}$ )}

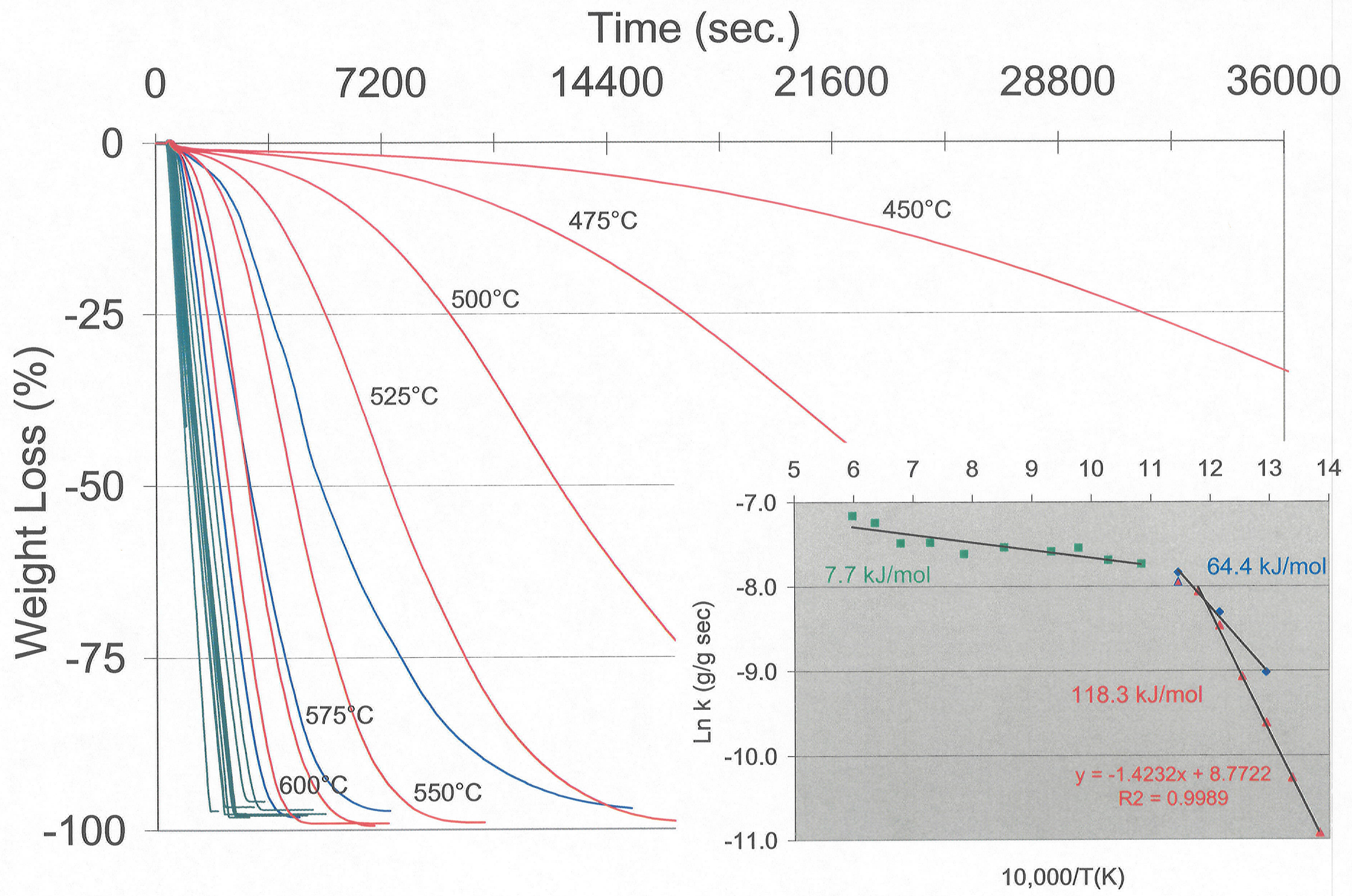




\section{Thermogravimetric Analysis of Pyro-Carbon Interphase}

\section{Percent Weight Loss Versus Time (oxygen flowing at $100 \mathrm{ccm}$ )}

Note: rates are also

$\mathrm{SiC/SiC}$ coupons with machined edges: the pyro-carbon interphase is oxidized in a flowing oxygen environment. The interphase is 3 wt \% of the composite (approximately 0.08 grams).

Time (hr)

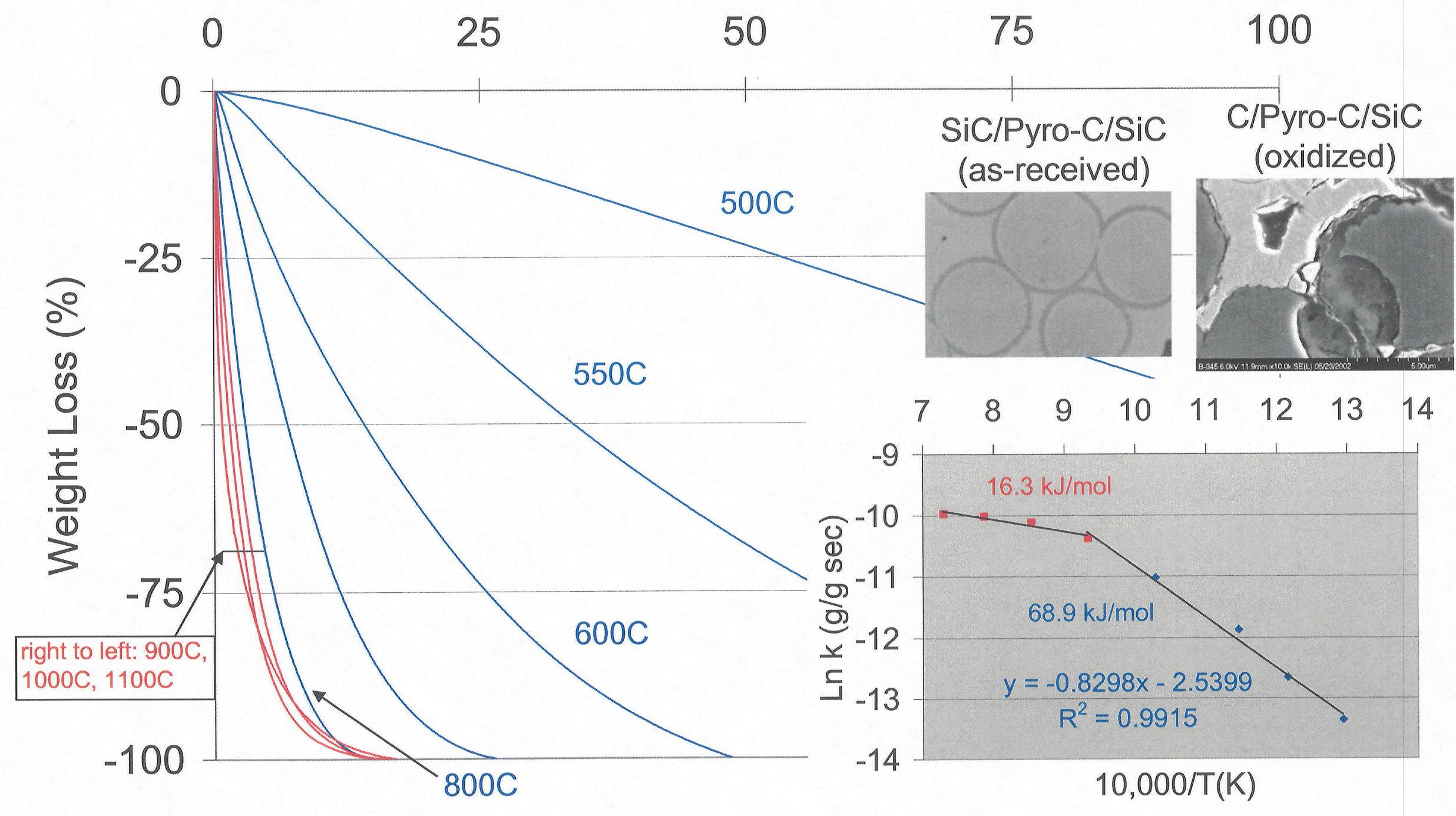


Thermogravimetric Analysis of $\mathrm{C} / \mathrm{SiC}$ Coupons

\section{Percent Weight Loss Versus Time (oxygen flowing at $100 \mathrm{ccm}$ )}

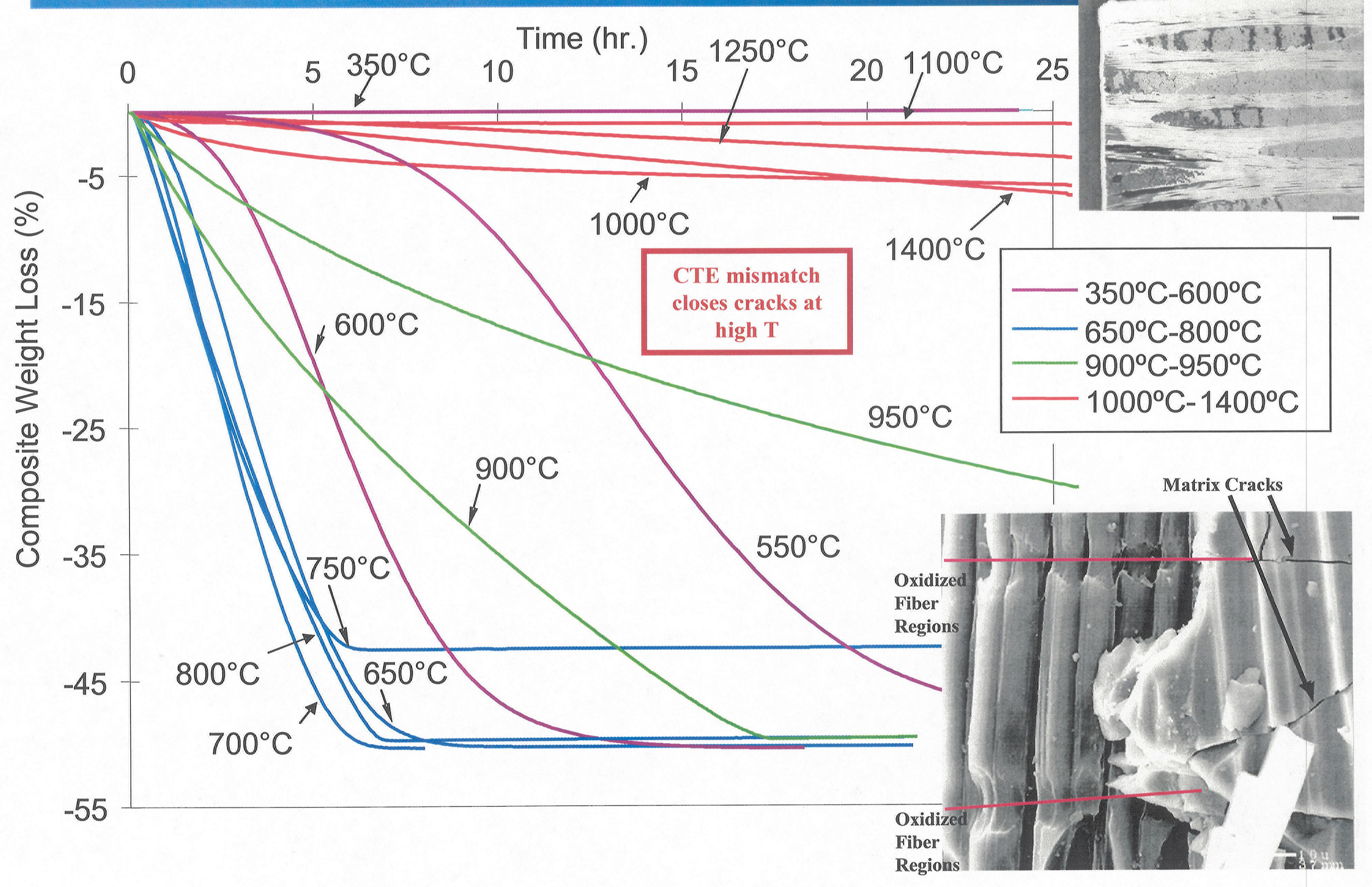




\section{Crack Opening Determined by Thermal and Load Strain}

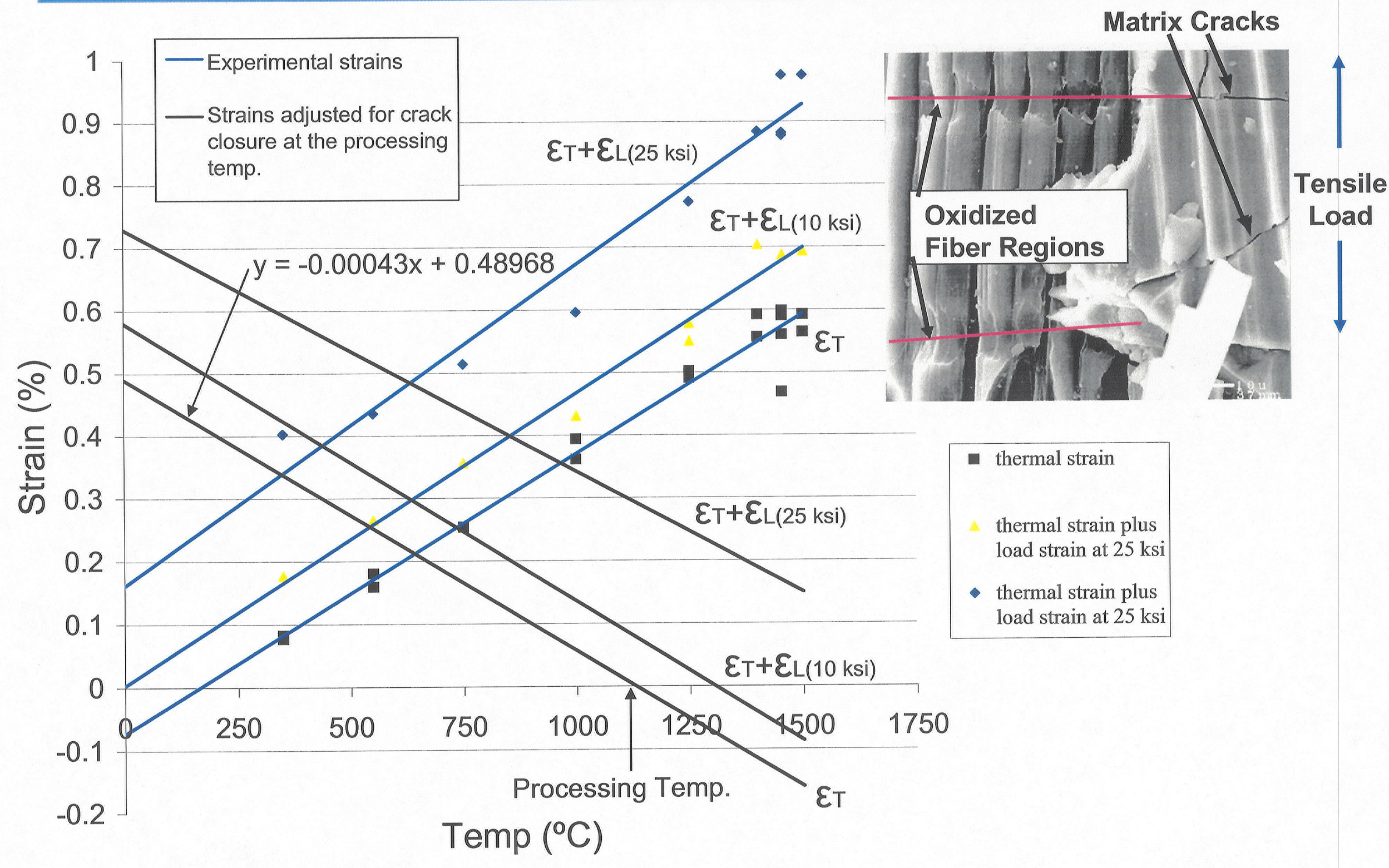




\section{Fractured Test Coupons From Stressed Oxidation Tests in Air}

$800^{\circ} \mathrm{C} 35 \mathrm{MPa} / 69 \mathrm{MPa} / 138 \mathrm{MPa}$ (1498 5 F ksi / 10 ksi / 20 ksi)

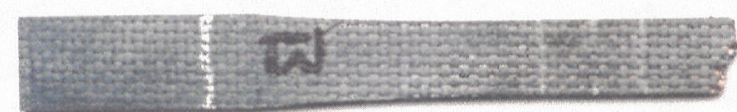

F6,706

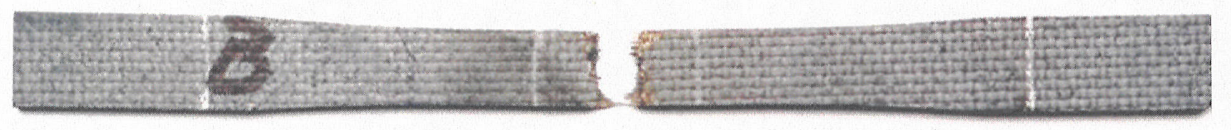

F6704 $800 \mathrm{C} / 10 \mathrm{ksi}$

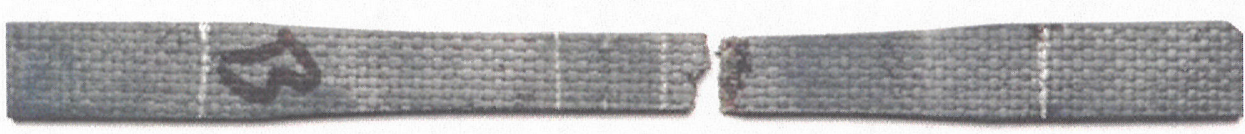

$1200^{\circ} \mathrm{C} 35 \mathrm{MPa} / 69 \mathrm{MPa} / 138 \mathrm{MPa}$ (2218 $\mathrm{F} 5 \mathrm{ksi} / 10 \mathrm{ksi} / 20 \mathrm{ksi})$
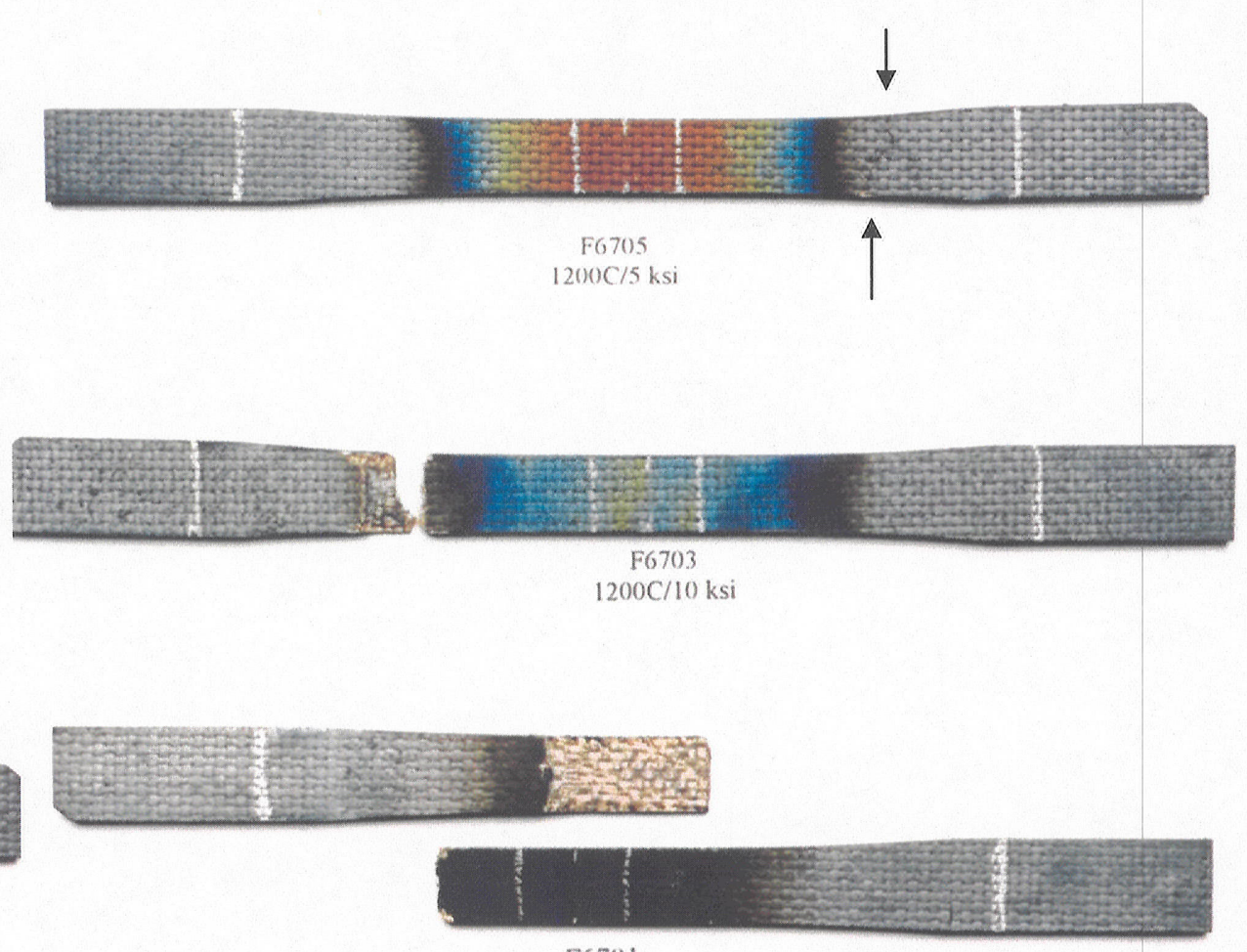
$F 6701$
$1200 \mathrm{C} / 20 \mathrm{ksi}$ 

In Air at $1200^{\circ} \mathrm{C}$
Polished Cross-Section from Gage (section width 0.13")

NASA
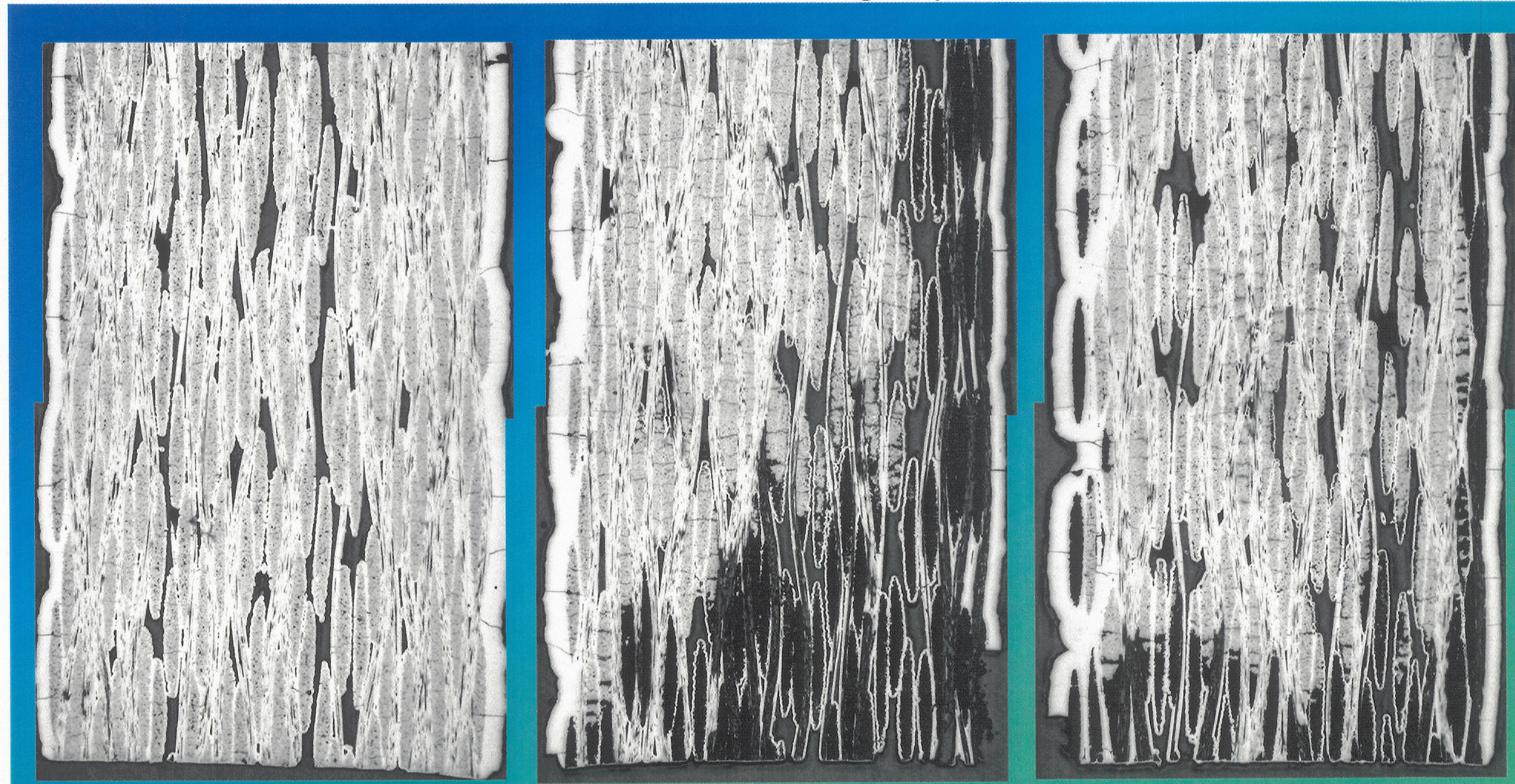

Stress (MPa): 35 69 138

Time to Failure (hr): 5.07 Failure Location: TG 2.33

Thermal Gradient (TG)
0.48

Gage 


\section{In Air at $1200^{\circ} \mathrm{C}$}

\section{Edges of Polished Cross-Sections}
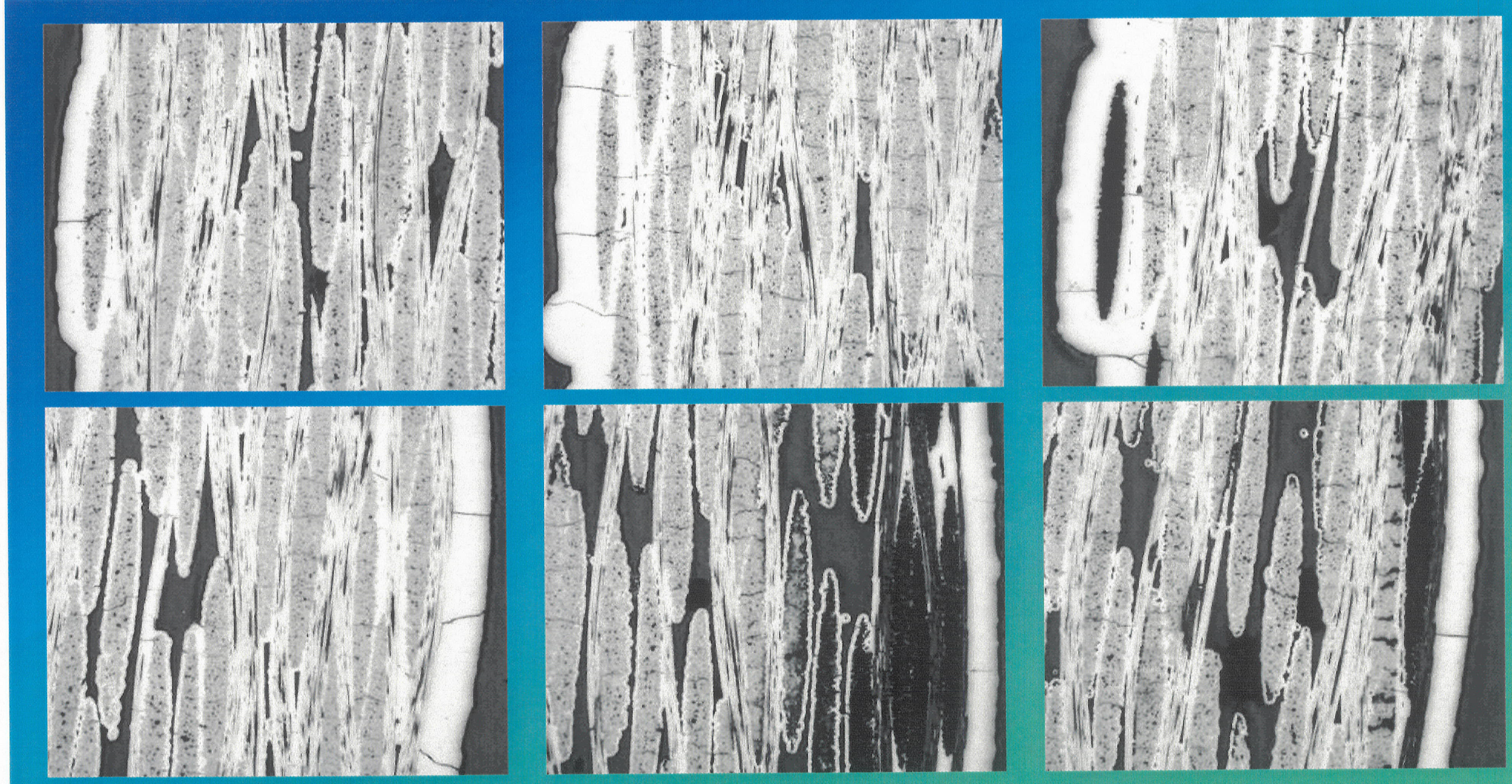

Stress (MPa):

35

69

138

Time to Failure (hr): 5.07

2.33

0.48

Failure Location:

TG

Thermal Gradient (TG)

Gage 
In Air at $800^{\circ} \mathrm{C}$
Polished Cross-Section from Gage (section width $\sim 0.13^{\prime \prime}$ )
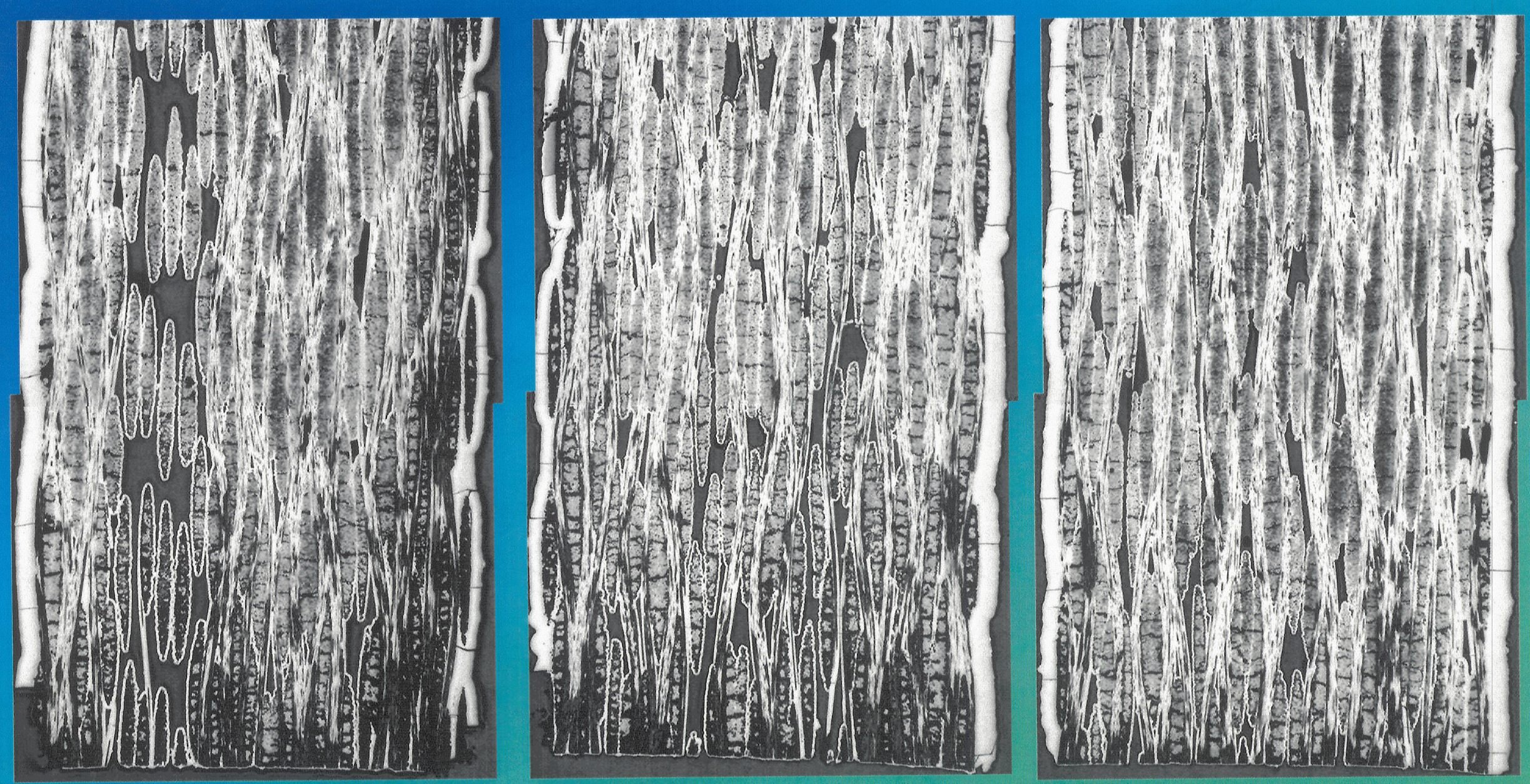

Stress (MPa):

35

69

138

Time to Failure (hr): 5.70

Failure Location: Gage

2.48

0.83

Gage

Gage 


\section{Edges of Polished Cross-Sections}
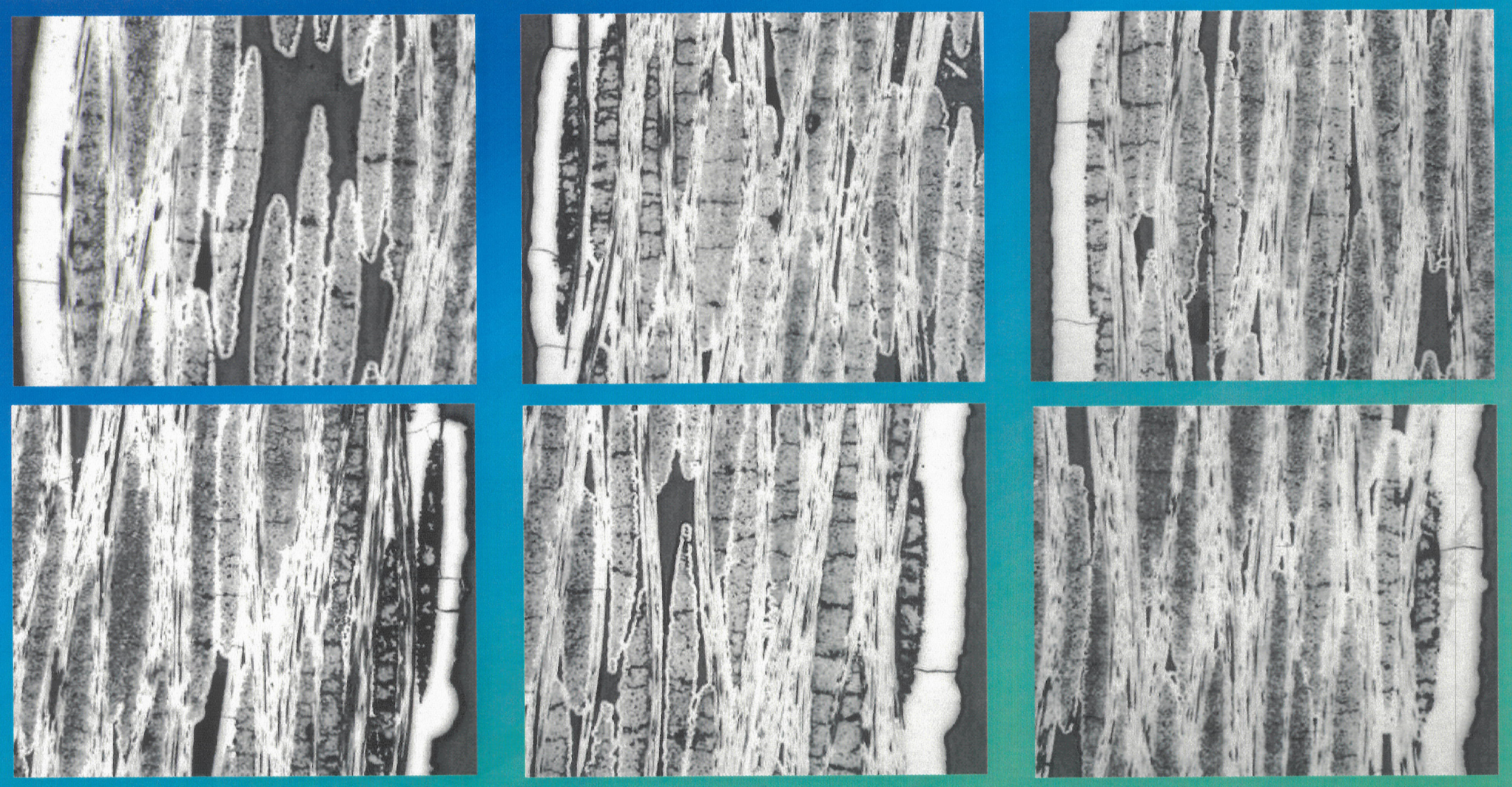

Stress (MPa):

Time to Failure (hr): 5.70 


\section{Strength Retained and Strain to Failure After Tensile Coupon Oxidation Exposures}

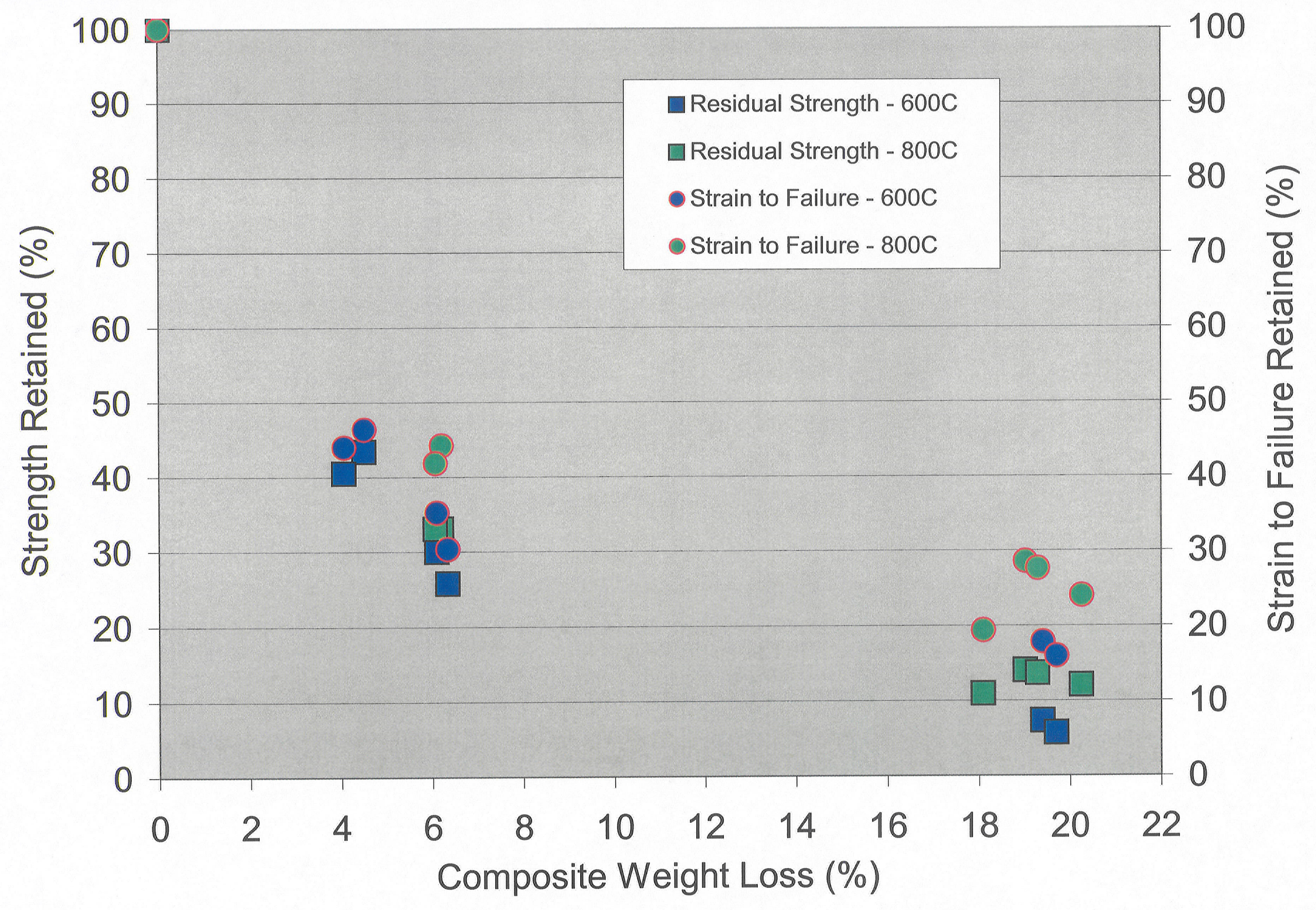




\section{Stressed Oxidation/Creep Rupture of C/SiC in Air Temperatures from $750^{\circ} \mathrm{C}-1500^{\circ} \mathrm{C}$, Stresses of 69 and $172 \mathrm{MPa}$ (10 and $25 \mathrm{ksi}$ )}

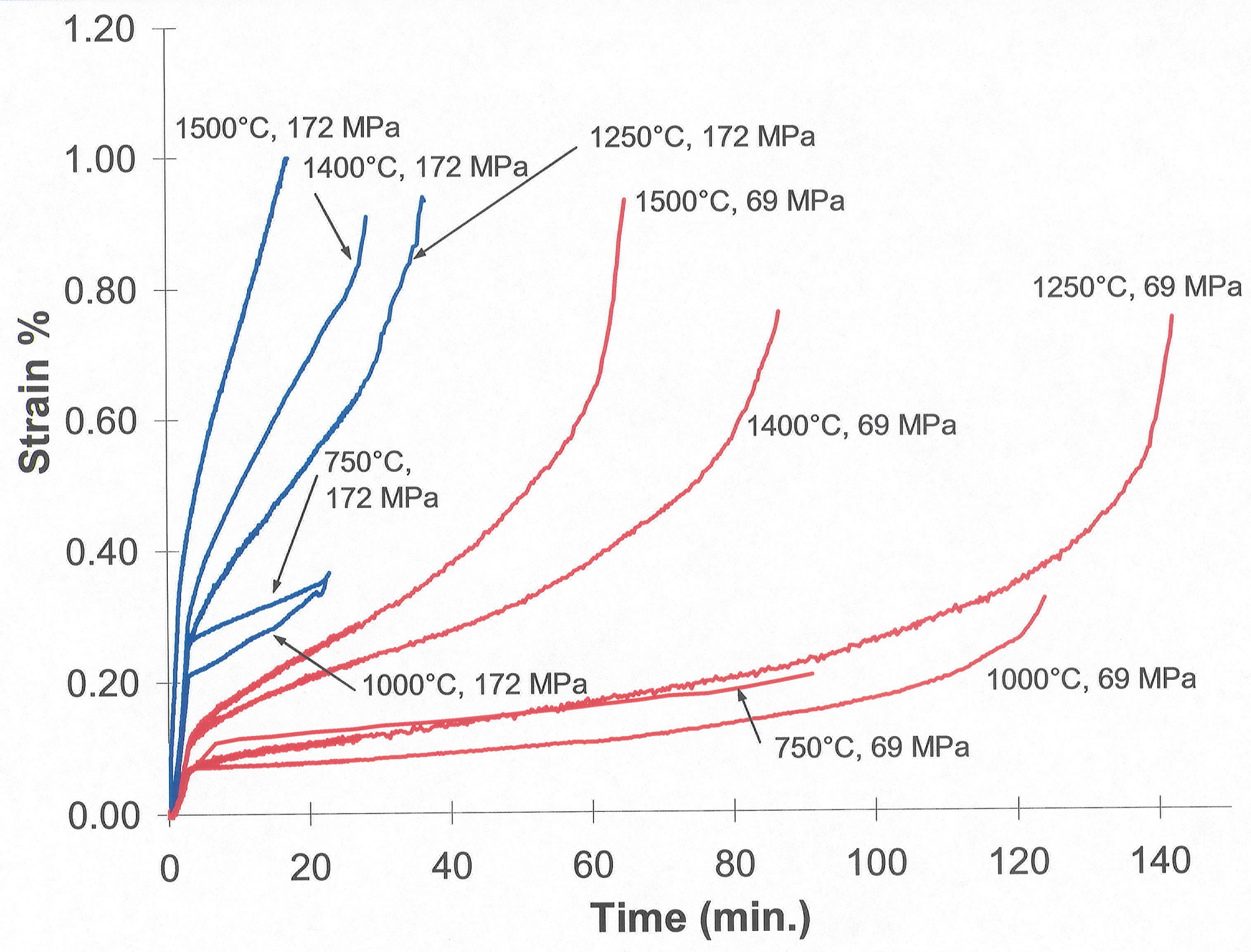




\section{C/SIC OXIDATION MODEL}

\section{Approach:}

Use a 2-D finite difference model that is physics based to simulate the oxidation of carbon fiber cross-sections in a cracked ceramic matrix composite.

Use theoretically and experimentally based variables in the model to keep track of oxygen concentrations and carbon recession and the time for carbon reactions.

\section{Product:}

A model that predicts a composite's strength reduction and/or time to failure based on the oxidation of load bearing fibers for such application variables as environment, temperature, and stress. 


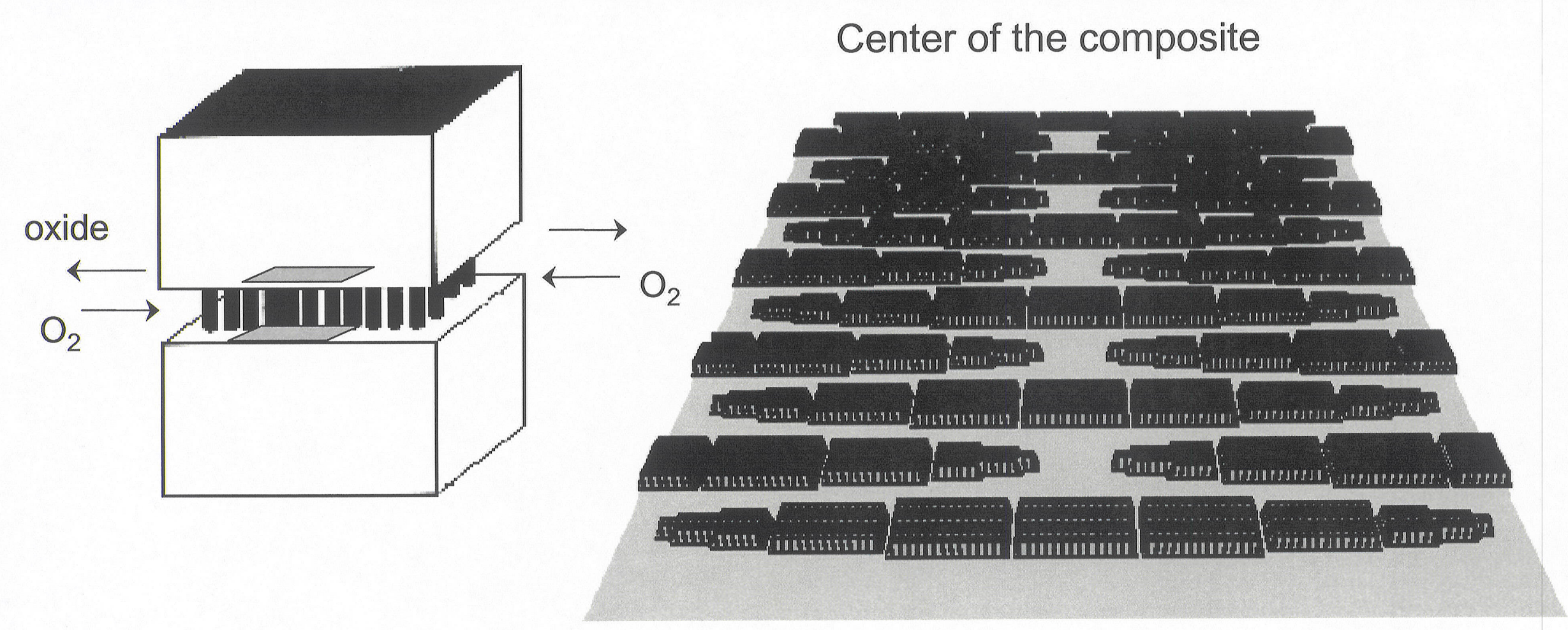

Front edge of the composite

One crack throughout the section is bridged by fiber tows and runs parallel to the gray plane. Also cracks perpendicular to the overall crack run through the individual fiber tows. 


\section{LINEAR-PARABOLIC OXIDATION KINETICS}

$$
\begin{array}{ll}
\frac{\mathrm{x}^{2}}{\mathrm{k}_{\mathrm{P}}}+\frac{\mathrm{x}}{\mathrm{k}_{1}}=\mathrm{t} & \text { Linearand ParabolioContributions } \\
\mathrm{k}_{1}=\left(\frac{1}{\mathrm{~N}}\right)\left(\chi \mathrm{C}_{\mathrm{T}}\right)(\mathrm{K}) & \text { LinearRateConstant } \\
\mathrm{k}_{1}=\left(\frac{1}{\mathrm{~N}}\right)\left(\frac{\chi \mathrm{P}}{\mathrm{RT}}\right)\left\{\mathrm{k}_{\mathrm{O}} \exp \left(\frac{-\mathrm{Q}}{\mathrm{RT}}\right)\right\} & \\
\mathrm{k}_{\mathrm{p}}=\frac{2 \mathrm{DC}}{\mathrm{N}} & \text { ParabolicRateConstant } \\
\mathrm{k}_{\mathrm{p}}=\left(\frac{4 \mathrm{DC}}{\mathrm{N}}\right) \ln \left\{\frac{\left.\left[(1+\chi)\left(\mathrm{D}_{\mathrm{k}} / \mathrm{D}\right)+1\right]\right\}}{\left[\left(\mathrm{D}_{\mathrm{k}} / \mathrm{D}\right)+1\right]}\right\} & 0_{2}+2 \mathrm{C} \Rightarrow 2 \text { COand KnudsenDiff. } \\
\mathrm{D}=\frac{5.9543 \times 10^{-24}\left[\left(1 / \mathrm{M}_{\mathrm{A}}\right)+\left(1 / \mathrm{M}_{\mathrm{B}}\right)\right]^{/ 2} \mathrm{~T}^{3 / 2}}{\left(\mathrm{P \sigma}_{\mathrm{AB}}^{2} \Omega_{\mathrm{AB}}\right)} & \text { DiffusionCoefficient } \\
\mathrm{D}_{\mathrm{k}}=8.575 \mathrm{~T}^{1 / 2} \mathrm{~d} & \text { KnudsenDiffusionCoefficient }
\end{array}
$$




\section{Model Representation}

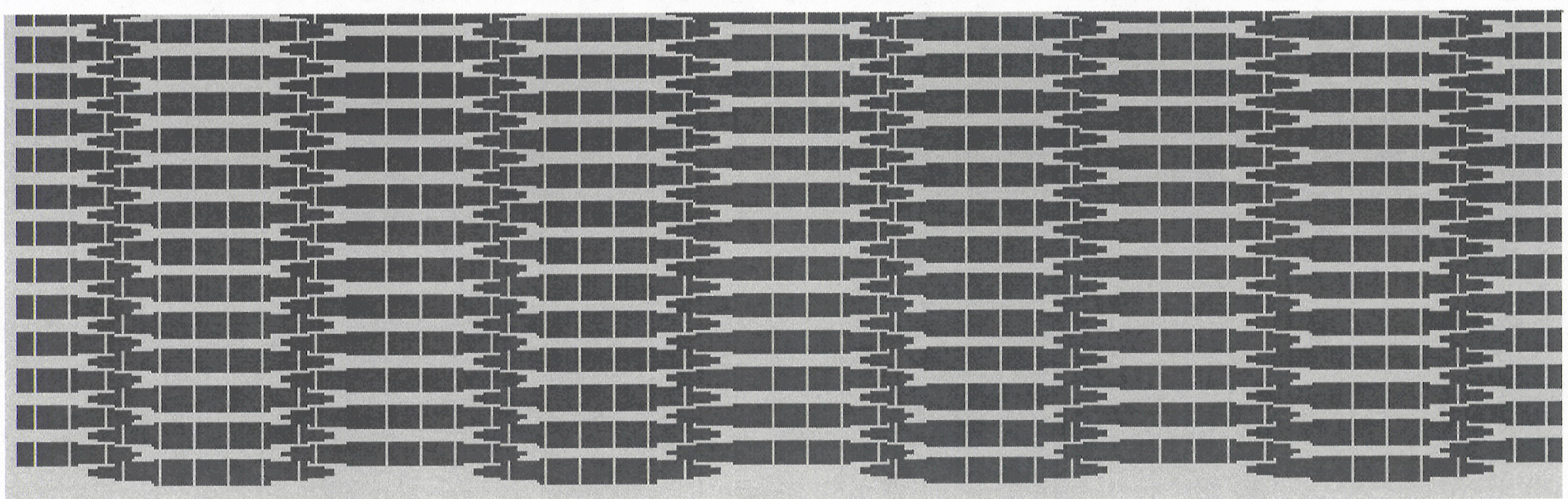

Model $1 / 4$ section

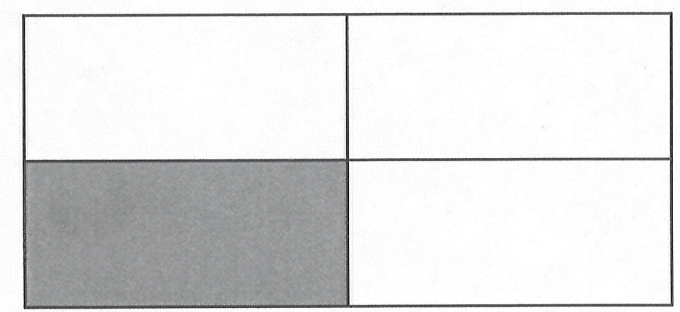

$D_{\text {eff }}=$ effective diffusion coefficient

$\epsilon=$ open void fraction (porosity)

$D_{A B}=$ interdiffusion coefficient $\mathrm{k}_{\mathrm{t}}=$ tortuosity factor

Representation allows for recession at both edges to be modeled.

Use different tortuousity factors for diffusion in the $\mathrm{x}$ and $\mathrm{y}$ directions.

$D_{\text {eff }}=\underline{\epsilon} \underline{D B}_{A B}$

Also allows for layout to be easily changed for different specimen geometries (volume and edge effect studies).

Quarter section is $161 \times 509$ grids, Tow array is $8 \times 13$, Cracked elliptical tows are $8 \times 80$ grids. 


\section{Results from the Oxidation Model - Oxidation Patterns}

\section{$800^{\circ} \mathrm{C}$}

\section{0 ppm Oxygen}

25\% Carbon Reacted Time: $79.1 \mathrm{hr}$.

$39.6 \%$ of the carbon grids are flawed.

Modeled Composite Cross-Section

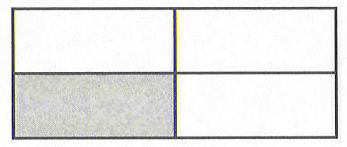

\section{$1200^{\circ} \mathrm{C}$}

\section{0 ppm Oxygen}

25\% Carbon Reacted Time: $35.6 \mathrm{hr}$.

$28.9 \%$ of the carbon grids are flawed (at least $5 \%$ oxidized).

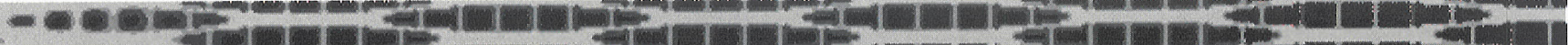

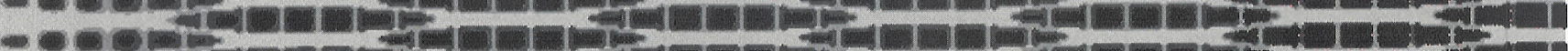

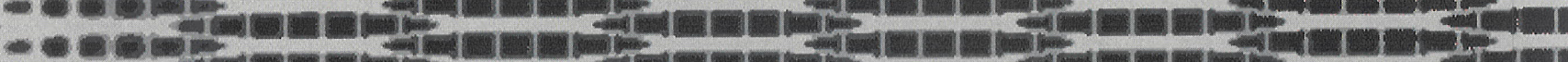

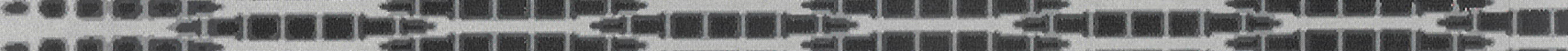
-

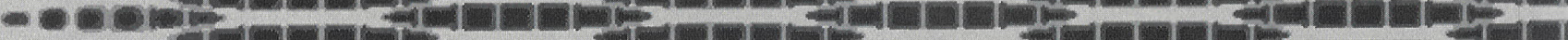

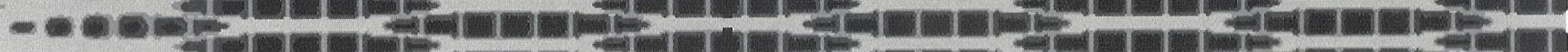

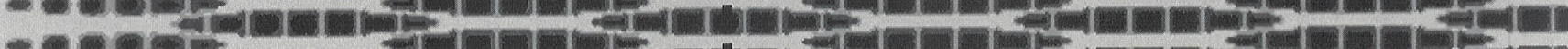

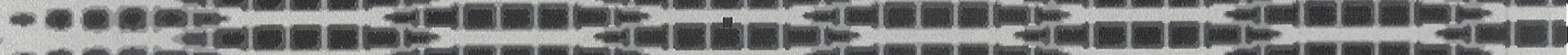

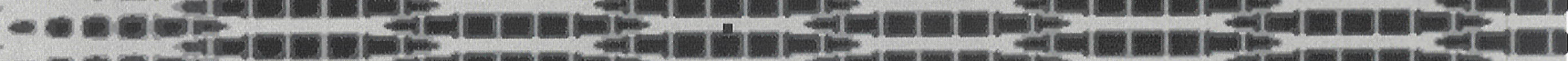

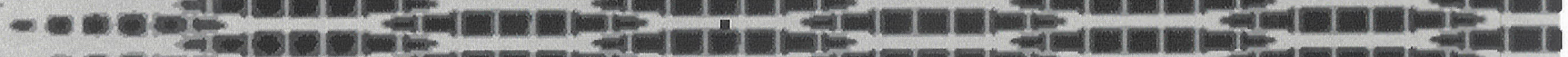

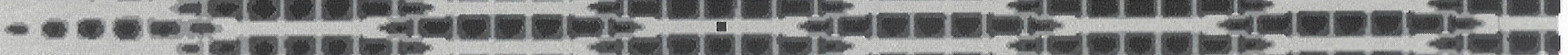

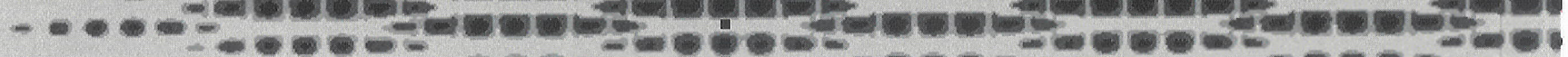

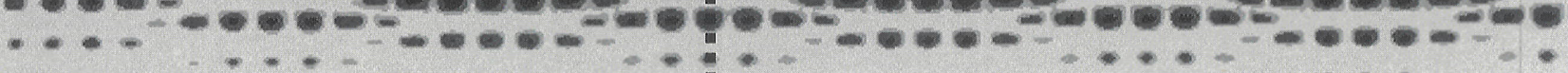

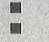

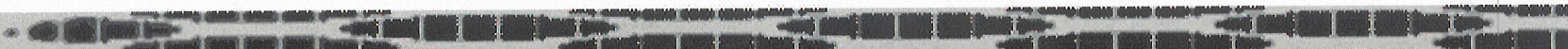
a

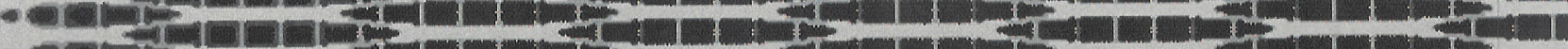
- a

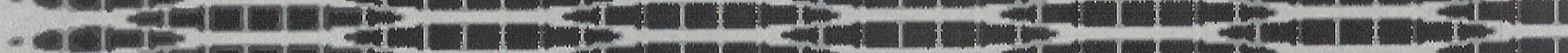

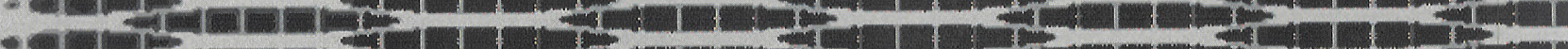

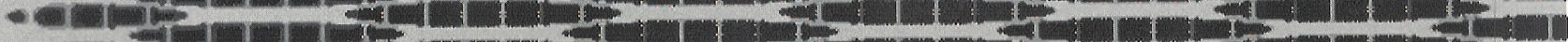

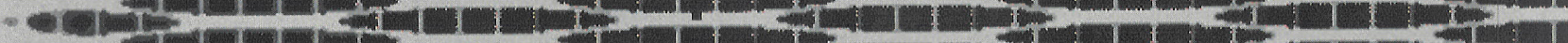

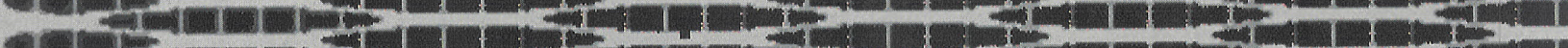

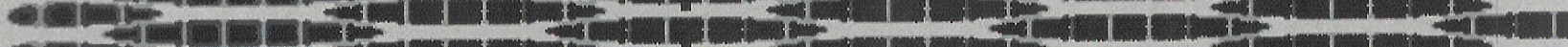

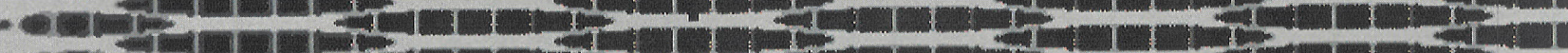
- Q

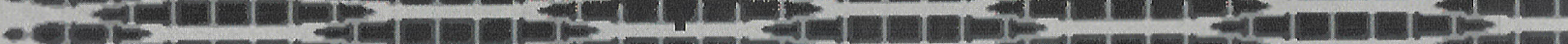

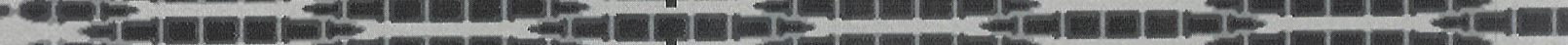

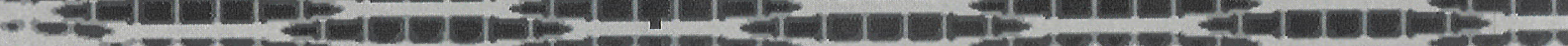

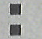


Results from the Oxidation Model

- Oxygen Concentrations (at 1000 ppm)

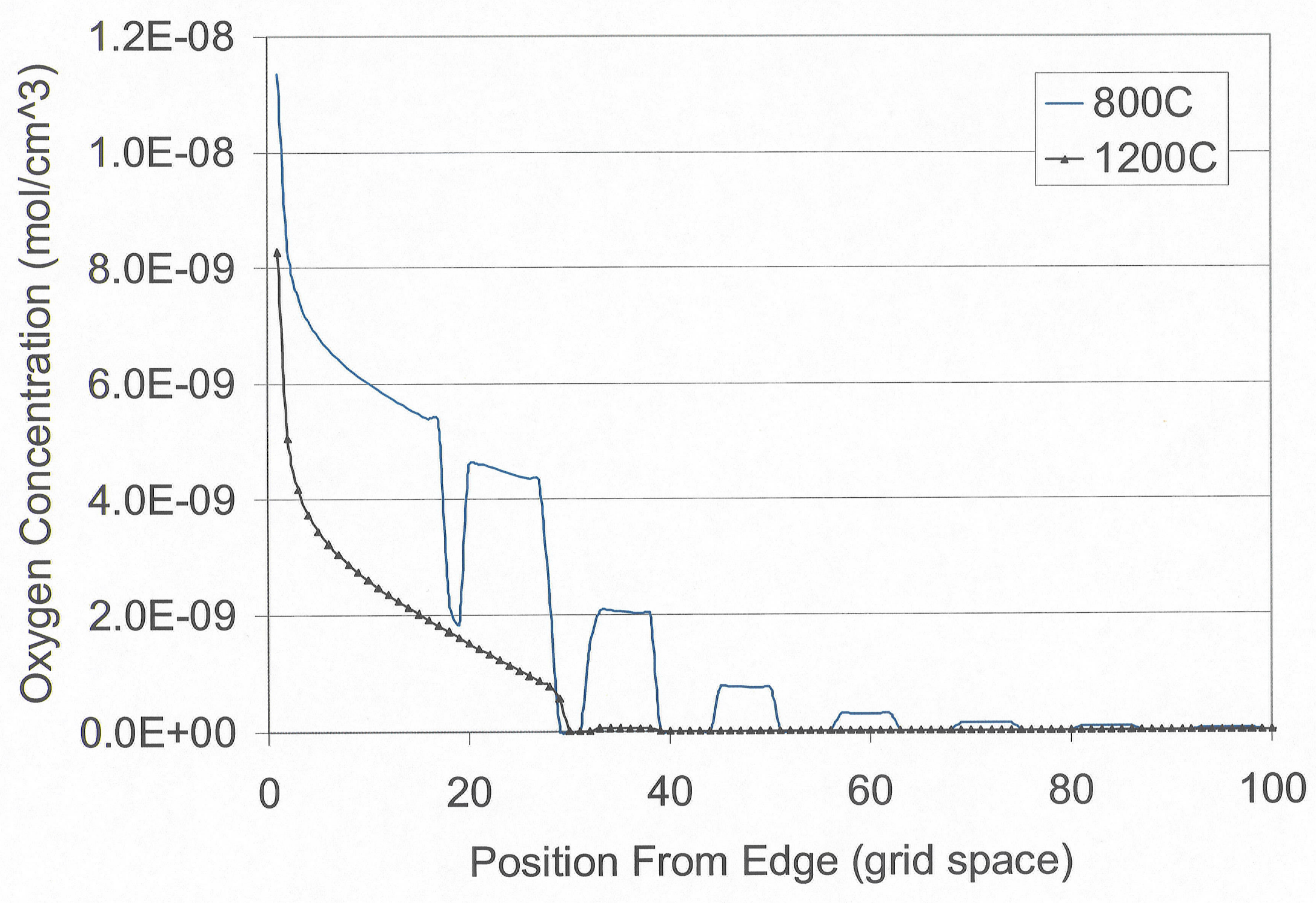




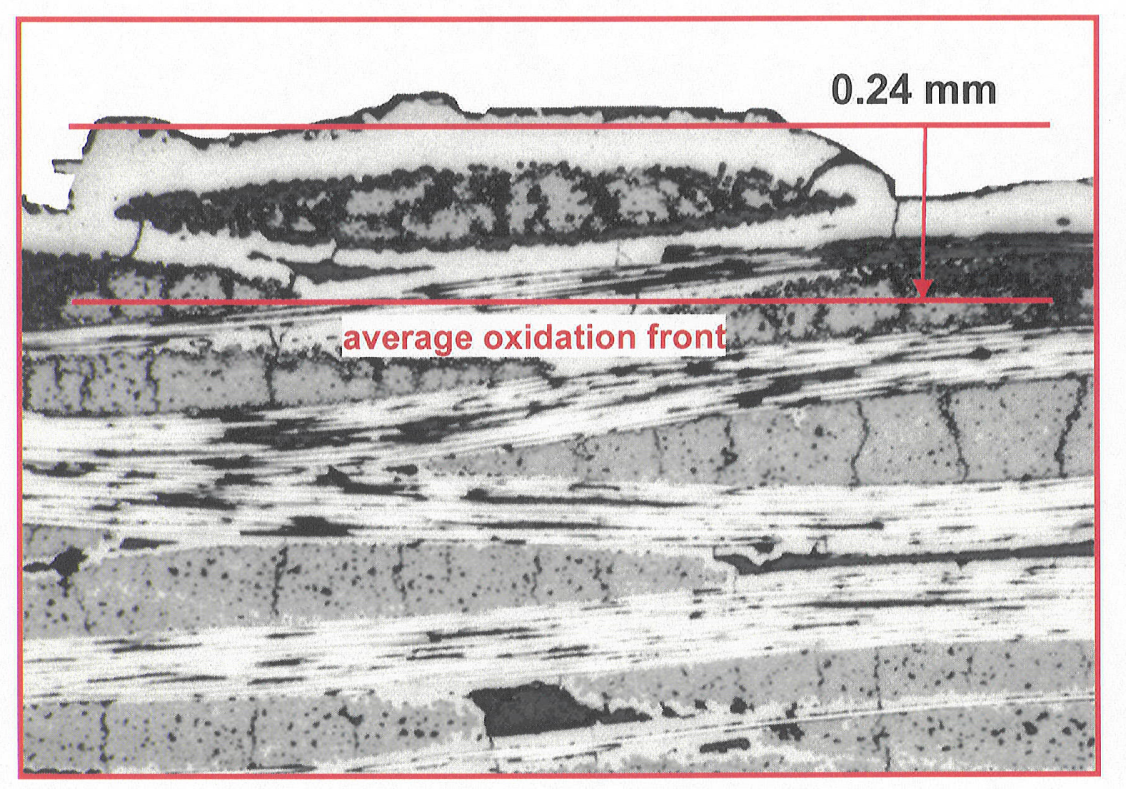

$9.7 \mathrm{hrs}$

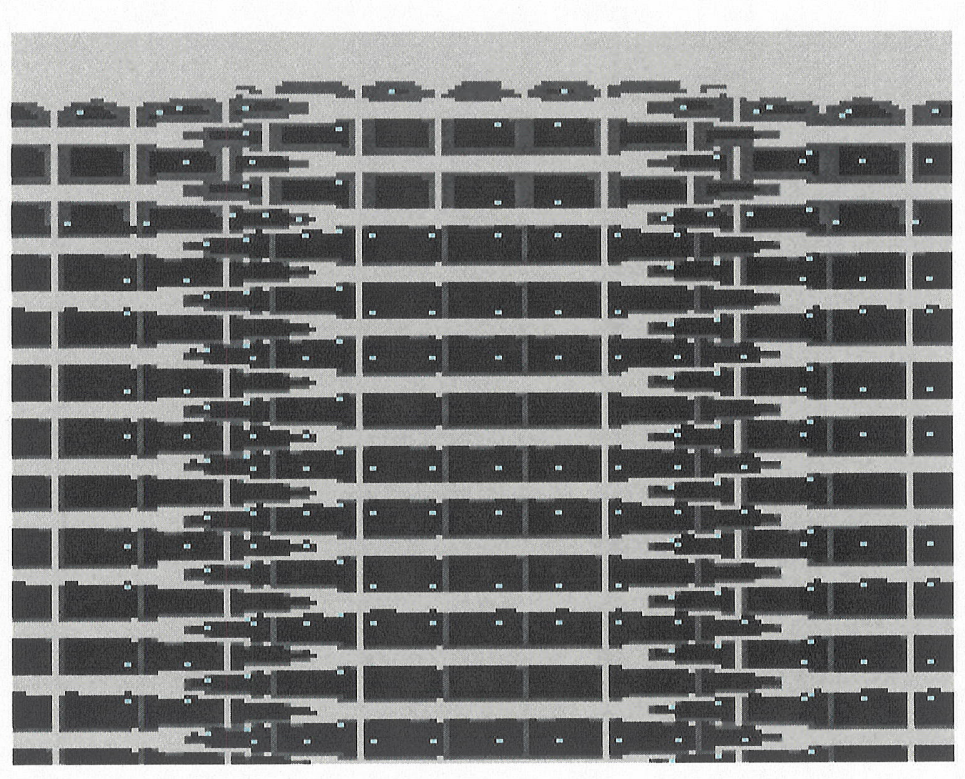

$10.1 \mathrm{hr}$

$8 \%$ carbon oxidized 


\section{Environmental Durability Task - Oxidation Inhibition of $\mathrm{C} / \mathrm{SiC}$}

\section{C/SiC Material Descriptions}

All 4 materials have the following characteristics:

- Manufactured by Honeywell Advanced Composites Inc. (HACl, now General Electric Power System Composites)

- 2D Plain weave fiber architecture

- Pyro-Carbon Alpha-3 interphase coating

- SiC matrix processed through isothermal CVI

The 4 materials have the following differences:

\begin{tabular}{|l|c|c|c|}
\hline & Treatment & Inhibitor in Matrix & Coating \\
\hline standard $\mathrm{C} / \mathrm{SiC}$ & none & none & $\mathrm{SiC}$ \\
\hline standard $\mathrm{C} / \mathrm{SiC}$ w/cbs & none & none & $\mathrm{SiC}, \mathrm{C}-\mathrm{B}-\mathrm{Si}$ \\
\hline enhanced $\mathrm{C} / \mathrm{SiC}$ & $1750^{\circ} \mathrm{C}$ & yes & $\mathrm{SiC}$ \\
\hline enhanced $\mathrm{C} / \mathrm{SiC}$ w/cbs & $1750^{\circ} \mathrm{C}$ & yes & $\mathrm{SiC}, \mathrm{C}-\mathrm{B}-\mathrm{Si}$ \\
\hline
\end{tabular}


TGA of CVI C/SiC Materials in Flowing Oxygen (100 ccm) at Temperatures of $600^{\circ} \mathrm{C}$ and $800^{\circ} \mathrm{C}$ - out to $25 \mathrm{hr}$

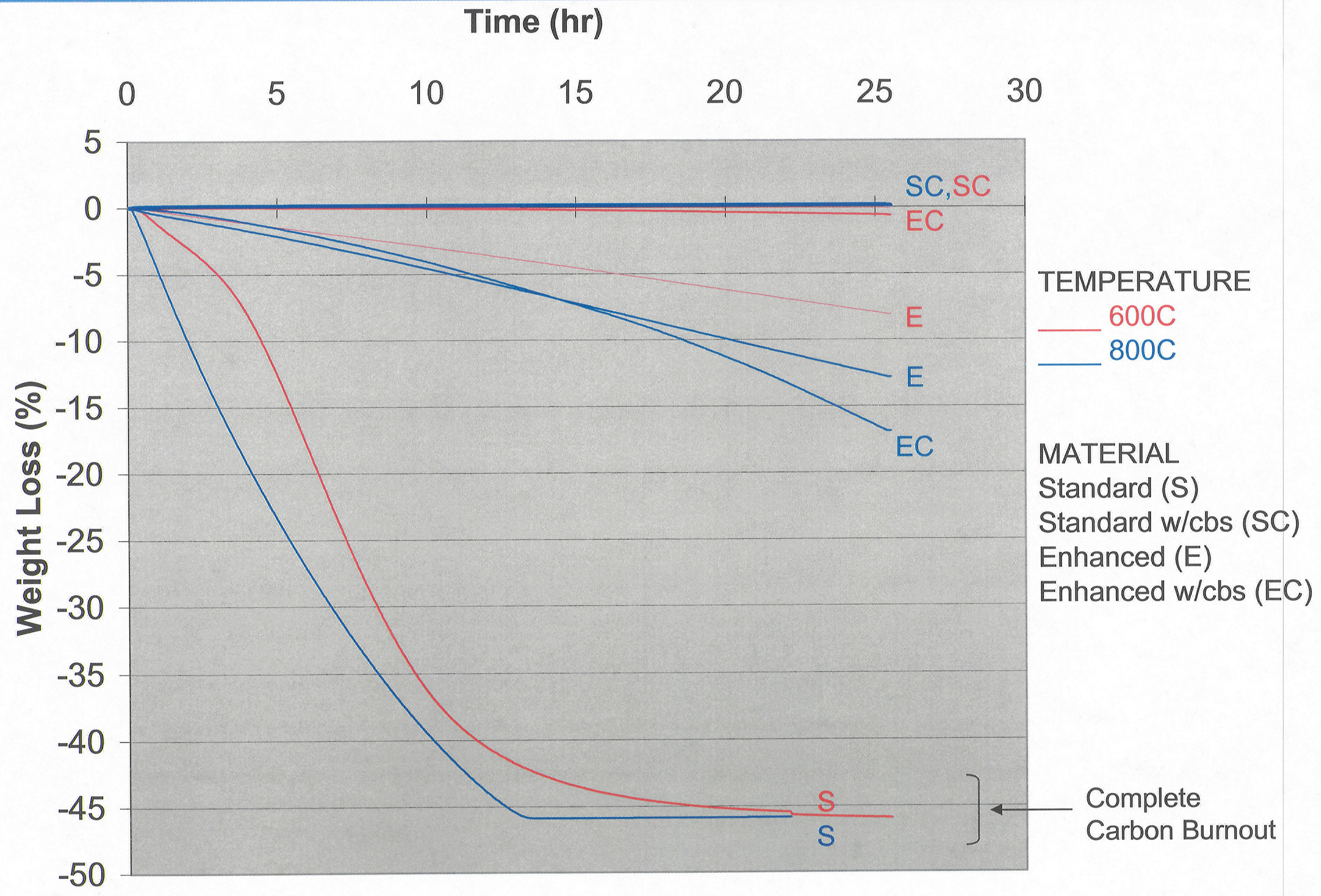




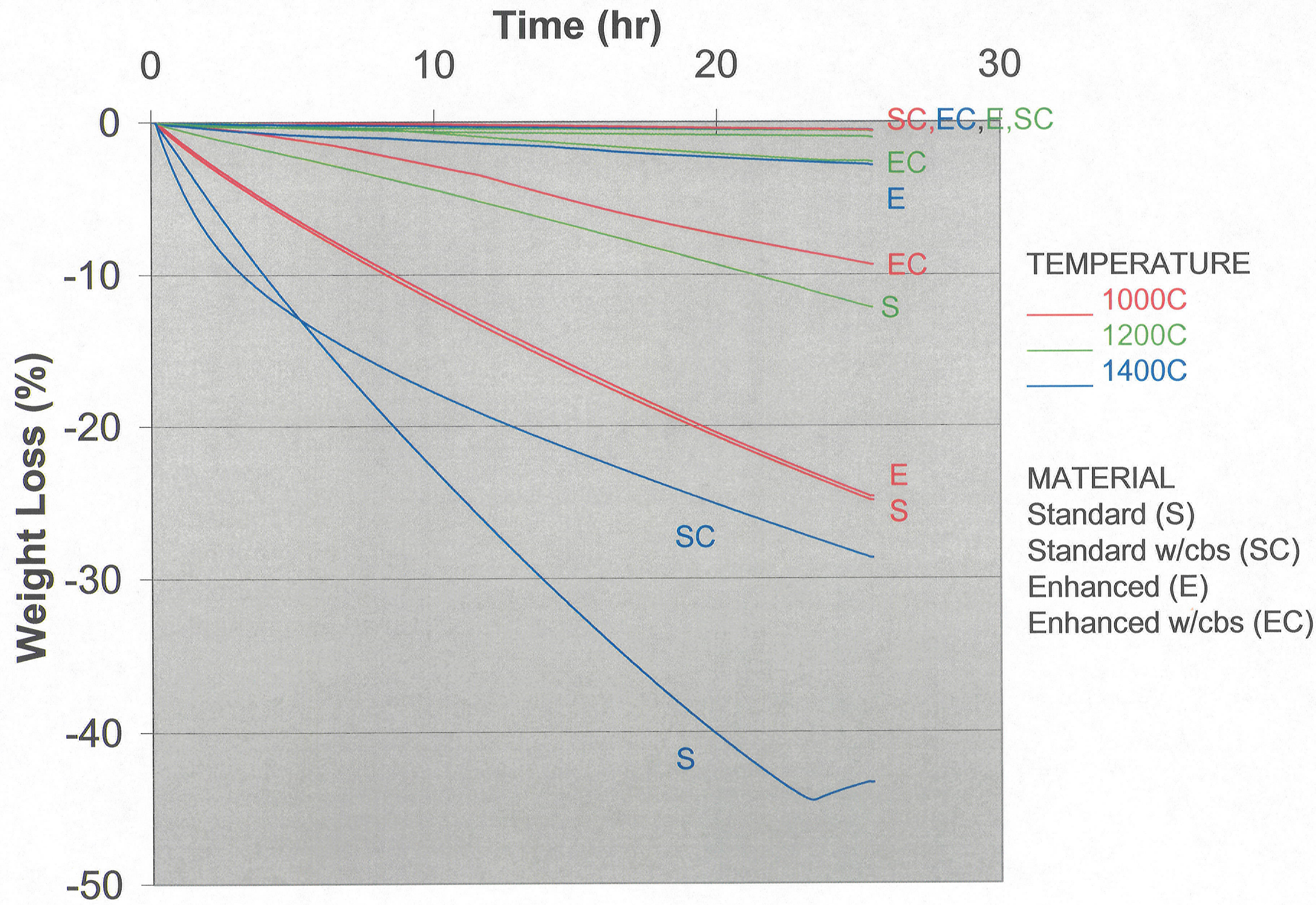


Composite Weight Loss After $25 \mathrm{hr}$ in TGA

(oxygen flowing at $100 \mathrm{ccm}$ )

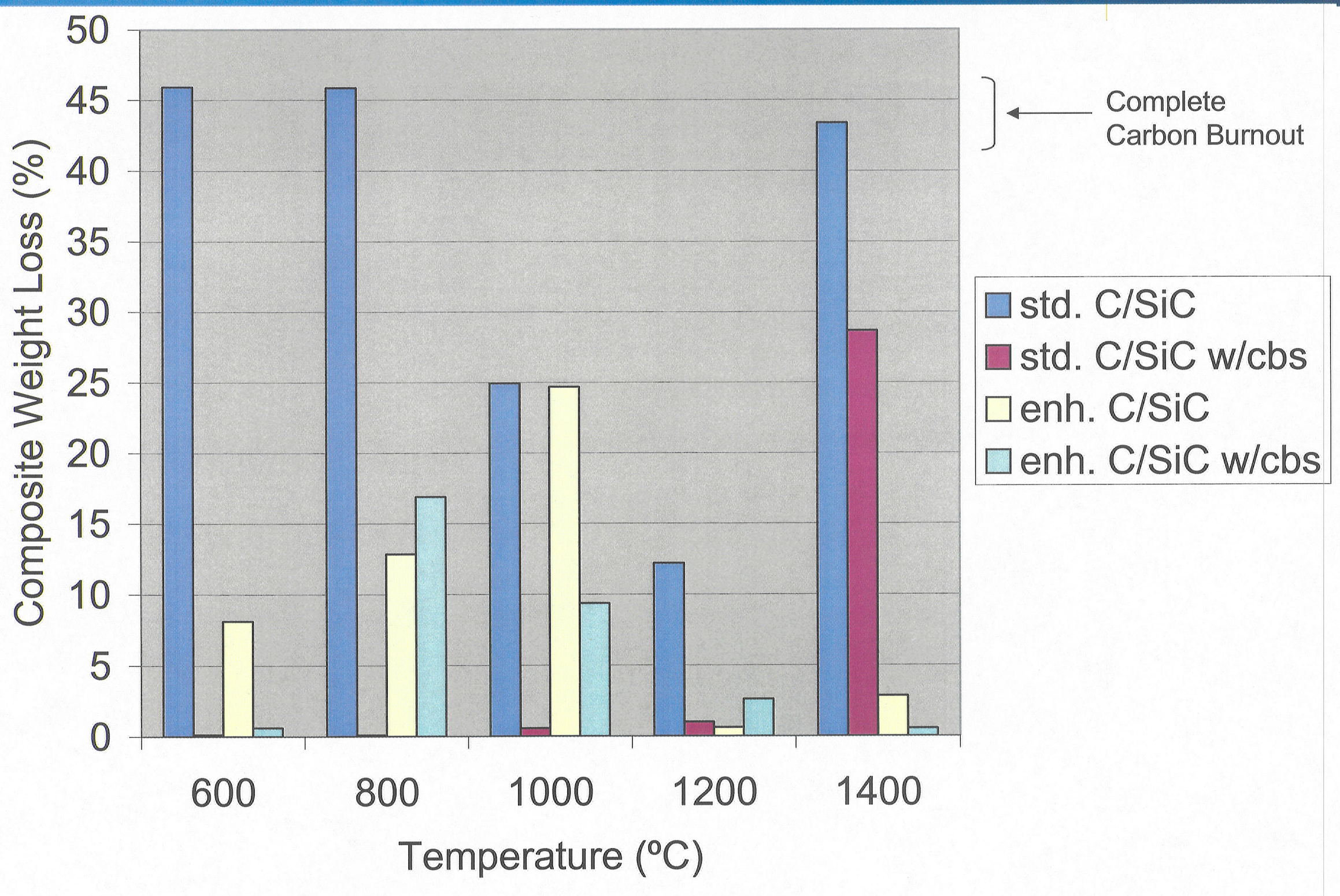




\section{Composite Weight Loss After $50 \mathrm{hr}$ in TGA (oxygen flowing at $100 \mathrm{ccm}$ )}

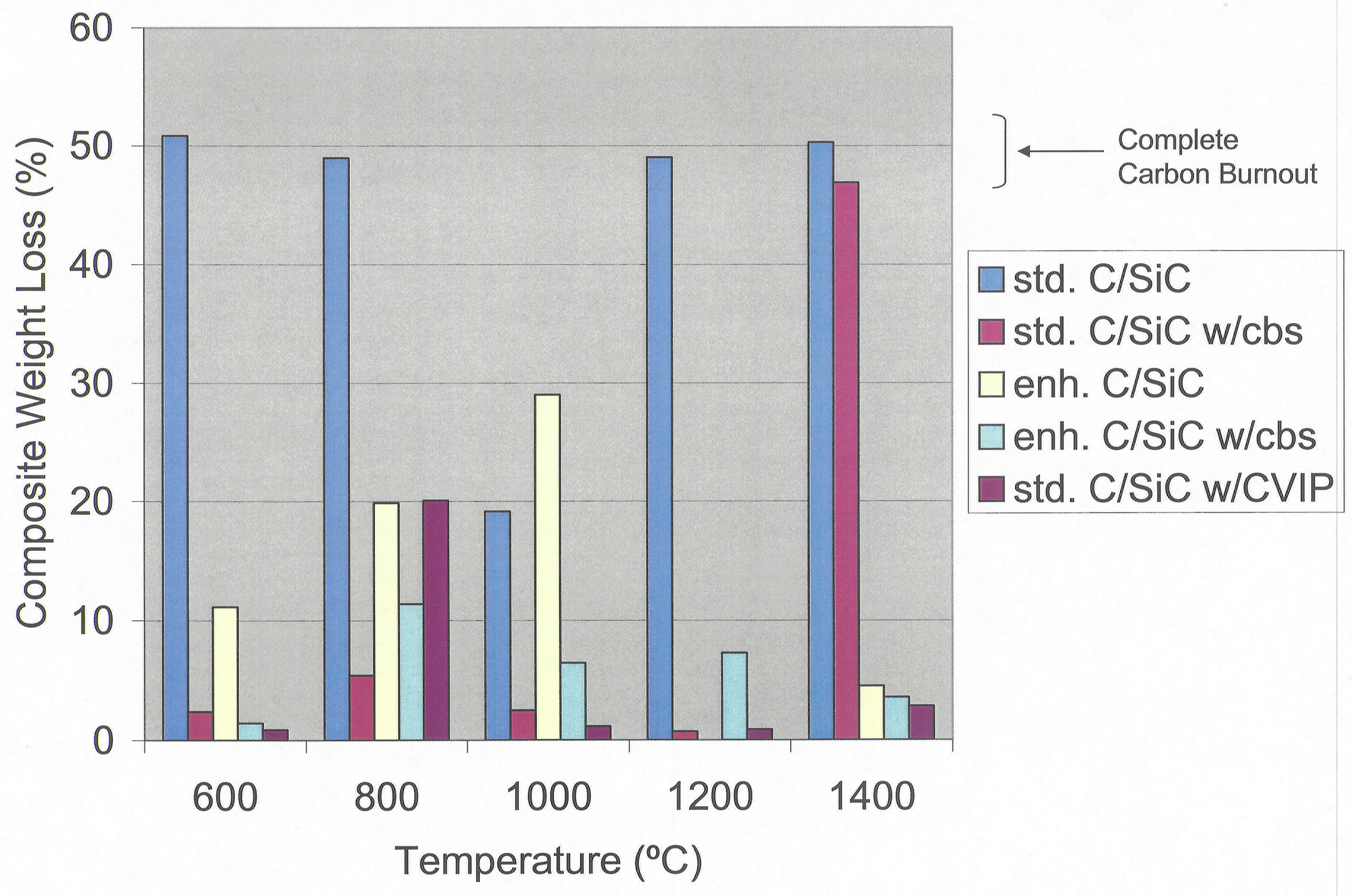




\section{Tensile Strength in Air}

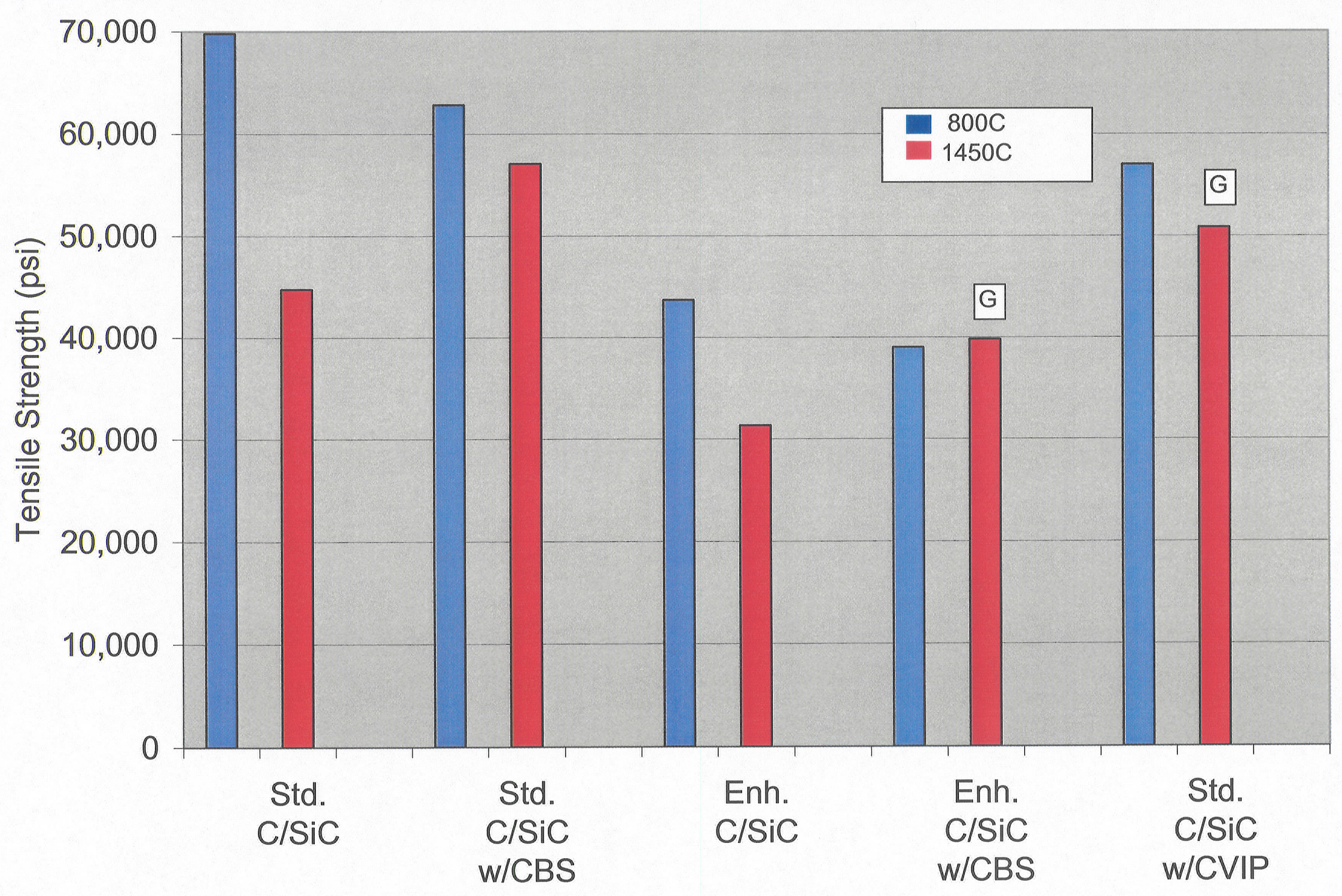




\section{Stressed Oxidation at $1454^{\circ} \mathrm{C} / 10 \mathrm{ksi}$ in Air}

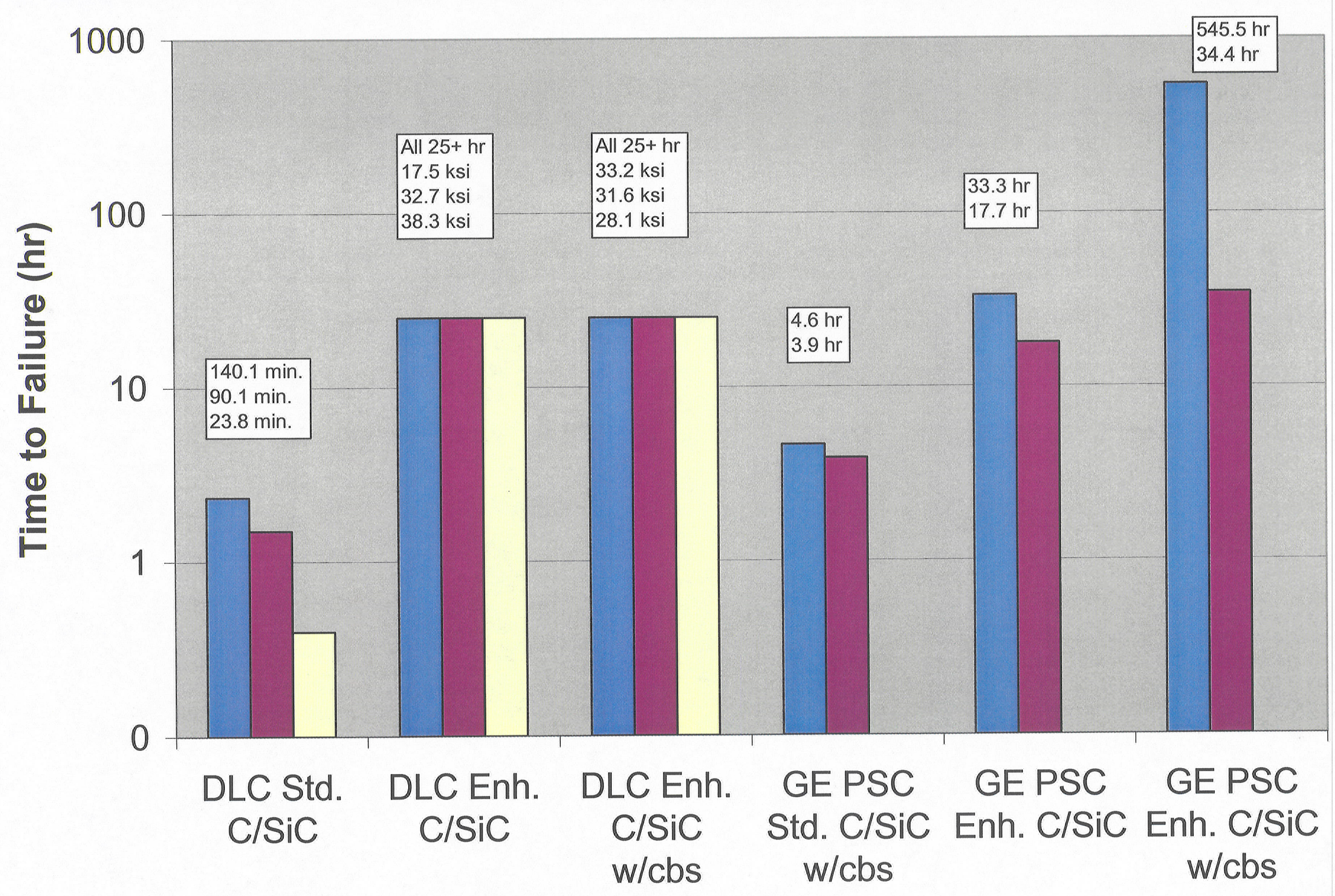


Strain Versus Time for Stressed Oxidation of $\mathrm{HACl}$ $\mathrm{C} / \mathrm{SiC}$ Materials $-\mathrm{Tests}$ at $1454^{\circ} \mathrm{C} / 69 \mathrm{MPa}\left(2650^{\circ} \mathrm{F} / 10 \mathrm{ksi}\right)$

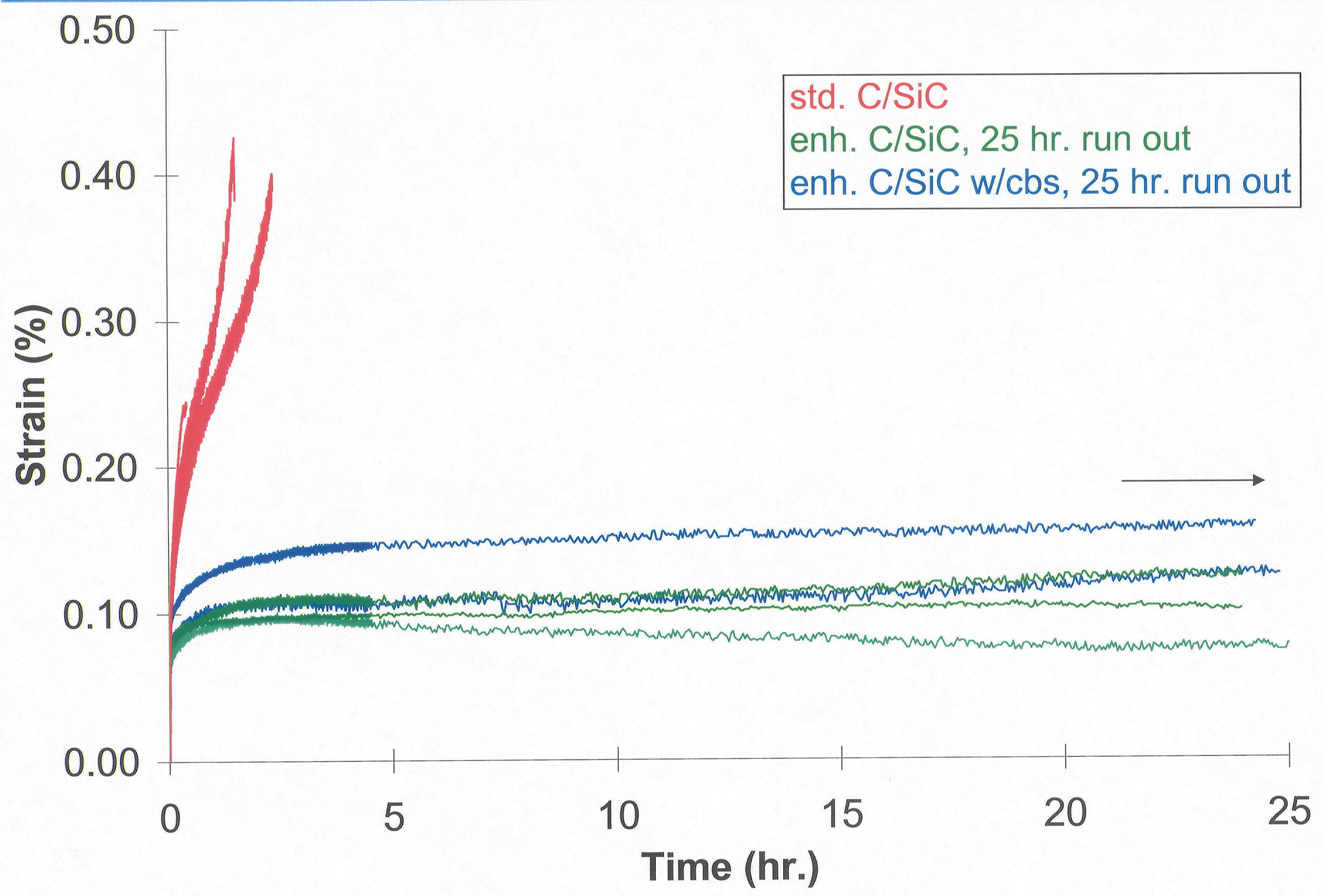




\section{Stressed Oxidation at $1454^{\circ} \mathrm{C} / 25 \mathrm{ksi}$ in Air}

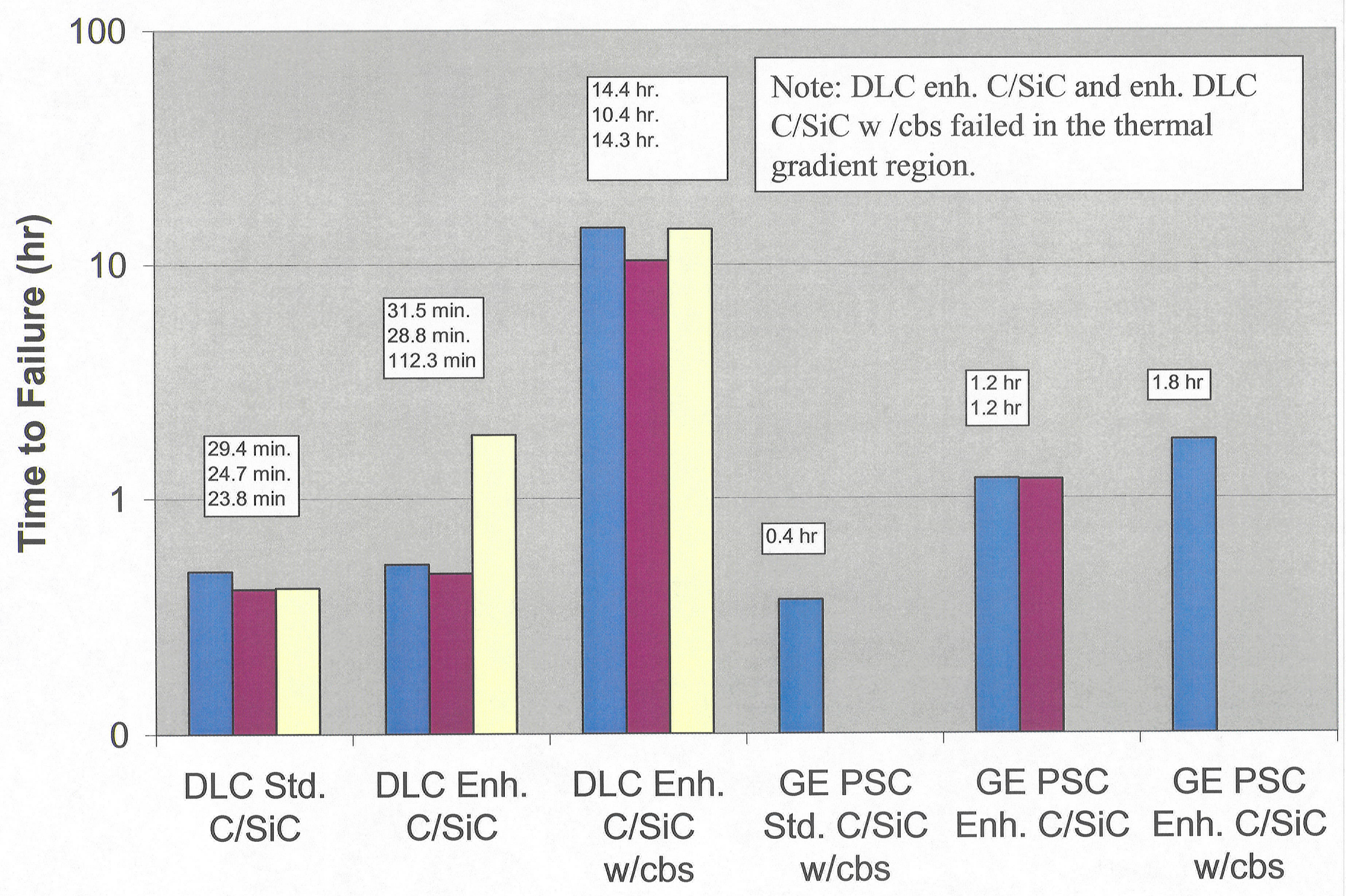




\section{Stressed Oxidation at $800^{\circ} \mathrm{C}$ in Air}

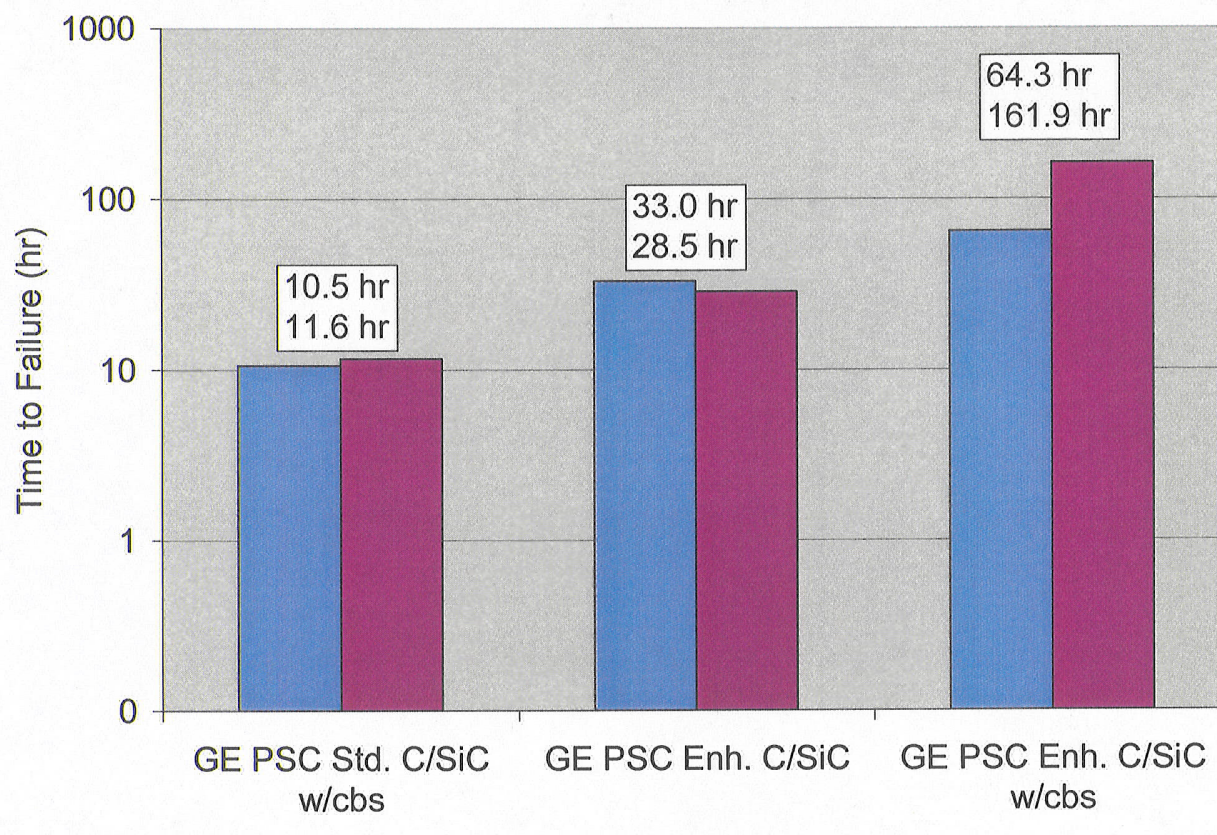

$800^{\circ} \mathrm{C} / 10 \mathrm{ksi}$ in Air

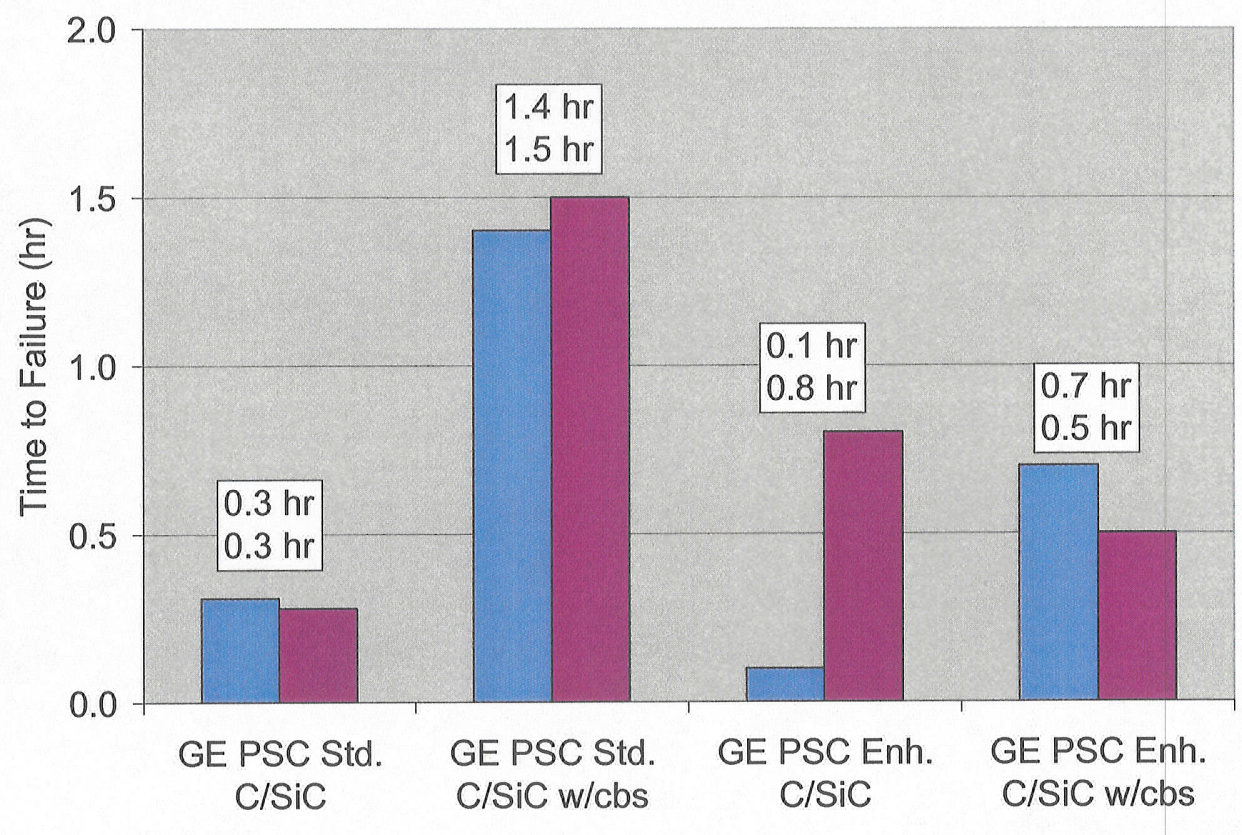

$800^{\circ} \mathrm{C} / 25 \mathrm{ksi}$ in Air 


\section{Summary/Conclusions}

Oxidation of the carbon constituents within $\mathrm{C} / \mathrm{SiC}$ occurs in two primary regimes.

- Reaction controlled regime: lower temperatures, oxygen saturates into the interior, oxidation rate is slower but oxidation is more widespread, embrittlement effect and low strains to failure.

- Diffusion controlled regime: higher temperatures, oxygen and carbon reactions occur quickly, reaction front moves inward, shrinking core, high strains to failure.

The T300 carbon fiber and the pyrolytic carbon interphase have different oxidation rates. In the lower temperature regime, the pyro-C has a slower reaction rates. Resulting activation energies suggest further testing is necessary.

Stress has a significant effect in opening cracks especially at high temperatures.

- In unstressed conditions: crack closure near processing temperature due to CTEs and silica formation. Cracks remain open at low temperatures.

- Under stress at high temperatures and at low temperatures, cracks are open and allow for oxygen ingress. Oxidation patterns according to kinetic regimes are observed. 


\section{Summary/Conclusions Continued}

The oxidation model is a useful tool for studying the oxidation kinetics, the effect of different variables (temperature, environment, porosity and tortuosity), and edge effects. With additional adjustment of the model (effective diffusion coefficients) to match experimental results, the model can be used to determine oxidation damage over time and determine strength reduction and failure.

Oxidation inhibitors can significantly improve the oxidation resistance of carbon in $\mathrm{C} / \mathrm{SiC}$ composites at intermediate $\left(800^{\circ} \mathrm{C}\right)$ and high temperatures $\left(1454^{\circ} \mathrm{C}\right)$. However, the approaches investigated in this study were only effective at low stress levels. 